\title{
Aerobic methanotrophic communities at the Red Sea brine-seawater interface
}

\author{
Rehab Z. Abdallah ${ }^{1}$, Mustafa Adel ${ }^{1,2}$, Amged Ouf ${ }^{1,2}$, Ahmed Sayed ${ }^{2+}$, Mohamed A. Ghazy ${ }^{2+}$, \\ Intikhab Alam ${ }^{3}$, Magbubah Essack ${ }^{3}$, Feras F. Lafi ${ }^{3}$, Vladimir B. Bajic ${ }^{3}$, Hamza El-Dorry ${ }^{1,2}$ and \\ Rania Siam ${ }^{1,2,4 *}$ \\ ${ }^{1}$ Biotechnology Graduate Program, American University in Cairo, Cairo, Egypt \\ ${ }^{2}$ Department of Biology, American University in Cairo, Cairo, Egypt \\ ${ }^{3}$ Computer, Electrical and Mathematical Sciences and Engineering Division, Computational Bioscience Research Center, King Abdullah University of Science and \\ Technology, Thuwal, Saudi Arabia \\ ${ }^{4}$ YJ-Science and Technology Research Center, American University in Cairo, Cairo, Egypt
}

Edited by:

Rex Malmstrom, DOE Joint

Genome Institute, USA

Reviewed by:

Maria Vila-Costa, Centre Estudis Avançats de Blanes (CEAB-CSIC), Spain

Marina G. Kalyuzhanaya, University of Washington, USA

*Correspondence:

Rania Siam, Biology Department, School of Science and Engineering

The American University in Cairo, AUC Avenue, PO Box 74, Cairo

11835, Egypt

e-mail: rsiam@aucegypt.edu

${ }^{\boldsymbol{t}}$ Present address:

Ahmed Sayed and Mohamed A.

Ghazy, Department of Biochemistry, Ain Shams University, Cairo, Egypt
The central rift of the Red Sea contains 25 brine pools with different physicochemical conditions, dictating the diversity and abundance of the microbial community. Three of these pools, the Atlantis II, Kebrit and Discovery Deeps, are uniquely characterized by a high concentration of hydrocarbons. The brine-seawater interface, described as an anoxic-oxic (brine-seawater) boundary, is characterized by a high methane concentration, thus favoring aerobic methane oxidation. The current study analyzed the aerobic free-living methane-oxidizing bacterial communities that potentially contribute to methane oxidation at the brine-seawater interfaces of the three aforementioned brine pools, using metagenomic pyrosequencing, $16 \mathrm{~S}$ rRNA pyrotags and $p m o A$ library constructs. The sequencing of $16 \mathrm{~S}$ rRNA pyrotags revealed that these interfaces are characterized by high microbial community diversity. Signatures of aerobic methane-oxidizing bacteria were detected in the Atlantis II Interface (ATII-I) and the Kebrit Deep Upper (KB-U) and Lower (KB-L) brine-seawater interfaces. Through phylogenetic analysis of pmoA, we further demonstrated that the ATII-I aerobic methanotroph community is highly diverse. We propose four ATII-I pmoA clusters. Most importantly, cluster 2 groups with marine methane seep methanotrophs, and cluster 4 represent a unique lineage of an uncultured bacterium with divergent alkane monooxygenases. Moreover, non-metric multidimensional scaling (NMDS) based on the ordination of putative enzymes involved in methane metabolism showed that the Kebrit interface layers were distinct from the ATII-I and DD-I brine-seawater interfaces.

Keywords: brine-seawater interfaces, aerobic methanotrophs, pmoA, 16S rRNA gene, Red Sea

\section{INTRODUCTION}

The Red Sea is a 450,000 square kilometer inlet of the Indian Ocean bordered by Egypt, Eritrea, Sudan and Djibouti to the west, Saudi Arabia and Yemen to the east and Egypt, Israel, Jordan and Saudi Arabia to the north. It has been described as an ocean in statu nascendi (Antunes et al., 2011a). The divergent movement of the African and Arabian tectonic plates exposed the hot mantle rock of the asthenosphere, causing a geothermal solution to be injected through the Earth's crust and mix with Red Sea seawater to form deep-sea brine pools (Oudin et al., 1984; Oudin and Thisse, 1988). One of the characteristics of the Red Sea is the presence of deep brines (Antunes et al., 2011b). The central rift of the Red Sea contains $\sim 25$ brine pools (Hartmann et al., 1998). Due to their distinctive physical and geochemical properties, deep-sea brine pools such as the Atlantis II Deep, Discovery Deep and Kebrit Deep are of particular interest. The Atlantis II Deep is known for its harsh and extreme environment, showing a temperature of $\sim 67.1^{\circ} \mathrm{C}$ and a salinity of 252 psu (Swift et al., 2012). The Discovery Deep is located southwest of Atlantis II and exhibits a temperature of $\sim 45^{\circ} \mathrm{C}$ and a salinity of 100 psu (Swift et al., 2012). On the other hand, the Kebrit Deep displays an ambient water temperature $\left(22-33^{\circ} \mathrm{C}\right)$ but is characterized by an elevated concentration of $\mathrm{H}_{2} \mathrm{~S}$ (ranging from 12 to $14 \mathrm{mg}$ sulfur/l) (Hartmann et al., 1998; Stoffers et al., 1998). Compared with the surface water methane concentration ( $40 \mathrm{nl} / \mathrm{l}-1.8 \mathrm{nmol} / \mathrm{l})$, these brine pools are also characterized by a high concentration of hydrocarbons, including methane, which seeps from the brine into the overlaying brine-seawater interface (Faber et al., 1998; Hartmann et al., 1998; Schmidt et al., 2003). The Kebrit Deep exhibits the highest concentration, which reaches a maximum of $476.2 \mathrm{mmol} / \mathrm{l}$, followed by the Atlantis II Deep and Discovery Deep, with concentrations of $5.5 \mathrm{mmol} / \mathrm{l}$ and $0.81 \mathrm{mmol} / \mathrm{l}$, respectively (Schmidt et al., 2003).

The overlaying brine-seawater interface is an aerobic methanerich layer; therefore, it represents a favorable environment for aerobic methane oxidation (Faber et al., 1998; Schmidt et al., 
2003). The methane concentration in interface layers can be as high as $276.2 \mathrm{mmol} / \mathrm{l}$ in the Kebrit Deep, $0.983 \mathrm{mmol} / \mathrm{l}$ in the Atlantis II Deep, and $0.81 \mathrm{mmol} / \mathrm{l}$ in the Discovery Deep (Schmidt et al., 2003). Moreover, carbon isotope analyses have suggested the occurrence of aerobic methane oxidation in the brine-seawater interface layers of the Atlantis II, Discovery and Kebrit Deeps (Faber et al., 1998; Schmidt et al., 2003). Positive shifts in 13C isotope levels, with $\delta^{13} \mathrm{C}-\mathrm{CH}$ values of $+5.7 \%$ PDB (Pee Dee Belemnite) and $+26.5 \%$ were reported in the Atlantis II and Discovery Deep interfaces, respectively (Schmidt et al., 2003).

Aerobic methanotrophic bacteria have been discussed in the scientific literature following the isolation of the first aerobic methanotroph (Bacillus methanicus) by Söhngen (1906), Hanson and Hanson (1996). To date, the only known facultative methanotrophs are type II methanotrophs, belonging to the $\alpha$-proteobacteria class, while type I methanotrophs belong to the $\gamma$-proteobacteria class (Hanson and Hanson, 1996; McDonald et al., 2008; Murrell, 2010). All aerobic methanotrophs possess the particulate methane monooxygenase (pMMO) gene, except for facultative methanotrophs of the Methylocella genus and the obligate methanotroph Methyloferula stellate (Dedysh et al., 2005; Vorobev et al., 2011). Facultative methanotrophs also possess the soluble methane monooxygenase (sMMO) gene (Dedysh et al., 2005; Dunfield et al., 2010; Belova et al., 2011; Im et al., 2011). The filamentous methane oxidizers, Crenothrix polyspora and Clonothrix fusca, were shown to be $\gamma$-proteobacteria that are closely related to methanotrophs (Stoecker et al., 2006; Vigliotta et al., 2007). However, Proteobacteria is not the only bacterial phylum that includes aerobic methanotrophs, as a class of aerobic methanotrophs belonging to the phylum Verrucomicrobia was found to thrive in highly acidic environments (Dunfield et al., 2007; Pol et al., 2007; Islam et al., 2008).

It is important to improve our knowledge of methaneoxidizing bacteria or methanotrophic communities, as they contribute to our understanding of methane cycling in the environment. Several studies have discussed the presence of aerobic methanotrophs in a wide range of marine habitats, including water column and sediment samples rich in methane collected from hydrothermal vents and hydrocarbon seeps (Wang et al., 2004; Nercessian et al., 2005; Yan et al., 2006; Tavormina et al., 2008, 2010; Kato et al., 2009; Moussard et al., 2009; Reed et al., 2009; Wasmund et al., 2009; Redmond et al., 2010). Studies examining the diversity of aerobic methanotrophic bacteria in the marine environment have mainly been carried out using the pmoA gene, encoding a $27-\mathrm{kDa}$ polypeptide subunit of particulate methane monooxygenase (pMMO), or the 16S rRNA gene. Novel marine-specific aerobic methanotrophs (OPU1, OPU3, and Group X) were discovered recently and have been suggested to be the major group involved in aerobic methane oxidation in oceanic systems (Elsaied et al., 2004; Tavormina et al., 2008, 2010; Wasmund et al., 2009). OPU1 and OPU3 represent a lineage that is distantly related to the type I methanotrophs (specifically the Methylocladum and Methylococcus genera) (Elsaied et al., 2004; Tavormina et al., 2008, 2010; Wasmund et al., 2009). However, Group X represents an out-group of both type I and type II methanotrophs (Tavormina et al., 2008, 2010; Wasmund et al., 2009). It is worth noting that 16S rRNA sequences were not recovered from the samples of these groups of methanotrophs (Tavormina et al., 2008; Wasmund et al., 2009). Except recently, candidate $16 \mathrm{~S}$ rRNA genes for these groups were identified in the Costa Rica convergent margin oxygen minimum zone (Tavormina et al., 2013). These lineages have been reported to be different from aerobic methanotrophs that have been identified in marine sediments (Tavormina et al., 2008, 2010; Wasmund et al., 2009). Thus, far, methane oxidation has only been studied in the three geochemically different brine pools in the Red Sea mentioned above (the Atlantis II Deep, Discovery Deep and Kebrit Deep) through carbon isotopes analyses, without any molecular and biological associations being obtained (Faber et al., 1998; Schmidt et al., 2003).

In this study, we investigate the aerobic methanotrophic bacterial communities that contribute to methane oxidation at the brine-seawater interface in these Red Sea brine pools. Because the brine-seawater interface layers exhibit differential levels of methane/oxygen, the abundance/diversity of the aerobic methanotrophic community should vary in the different seawater layers. In particular, the presence of type I methanotrophs, which are known to dominate marine environments, is expected (Nercessian et al., 2005; Yan et al., 2006; Tavormina et al., 2008; Reed et al., 2009). We adopted a comprehensive approach based on the shotgun pyrosequencing of metagenomic sequencing libraries, in addition to the use of $16 \mathrm{~S}$ rRNA pyrotags and pmoA library analyses.

\section{MATERIALS AND METHODS SAMPLE COLLECTION}

At the Atlantis II Interface (ATII-I), Discovery Deep Interface (DD-I) and Kebrit Deep Lower Interface (KB-L), 240 liters of water was collected, while 120 liters was collected from the Kebrit Deep Upper Interface (KB-U) during the KAUST Red Sea R/V Aegaeo expedition in spring 2010 (Table 1). At ATII, samples were collected from the overlying water column from depths of 50, 200, 700, and $1500 \mathrm{~m}$ (Siam et al., 2012; Ferreira et al., 2014). The samples from the ATII overlying water column were used for the subtraction of common reads from the different brine/interface layers. These large volumes of water were collected using shipboard Niskin bottles connected to CTDs (conductivity, temperature, and depth sensors) at the depths indicated in Table 1.

\section{Table 1 | Description of samples.}

\begin{tabular}{lccl}
\hline $\begin{array}{l}\text { Sample } \\
\text { description }\end{array}$ & $\begin{array}{c}\text { Latitude/ } \\
\text { Longitude }\end{array}$ & $\begin{array}{c}\text { Sample } \\
\text { depth }\end{array}$ & $\begin{array}{l}\text { Environmental } \\
\text { library description }\end{array}$ \\
\hline $\begin{array}{l}\text { Atlantis II } \\
\text { interface (ATII-I) }\end{array}$ & $\begin{array}{r}21.60528 / \\
38.2025\end{array}$ & $1996-2025 \mathrm{~m}$ & $\begin{array}{l}\text { pmoA/16S } \\
\text { rRNA/Pyrosequencing }\end{array}$ \\
\hline $\begin{array}{l}\text { Discovery } \\
\text { interface (DD-I) }\end{array}$ & $\begin{array}{r}21.28639 / \\
38.28722\end{array}$ & $2026-2042 \mathrm{~m}$ & $\begin{array}{l}16 \mathrm{~S} \\
\text { rRNA/Pyrosequencing }\end{array}$ \\
\hline $\begin{array}{l}\text { Kebrit upper } \\
\text { interface (KB-U) }\end{array}$ & $\begin{array}{r}24.7187 / \\
36.2888\end{array}$ & $1468 \mathrm{~m}$ & $\begin{array}{l}\text { pmoA/16S } \\
\text { rRNA/Pyrosequencing }\end{array}$ \\
\hline $\begin{array}{l}\text { Kebrit lower } \\
\text { interface (KB-L) }\end{array}$ & $\begin{array}{r}24.7187 / \\
36.2888\end{array}$ & $1469 \mathrm{~m}$ & $\begin{array}{l}16 S \\
\text { rRNA/Pyrosequencing }\end{array}$
\end{tabular}


Oxygen saturation was measured using a SeaBird DO sensor mounted to the CTDs. For all of the samples, with the exception of KB-U, the CTD was deployed twice at the same depth to collect the required water volume. Sequential microbial size fractionation was performed on Millipore Mixed Cellulose Esters filters (Nitrocellulose/Cellulose Acetate) with pore sizes of 3, 0.8, and $0.1 \mu \mathrm{m}$, only the last of which was further processed and analyzed. The filters were collected and stored in sucrose lysis buffer (Rusch et al., 2007) and were held at $-20^{\circ} \mathrm{C}$ until delivery to the laboratory at the American University in Cairo, where they were stored in a $-80^{\circ} \mathrm{C}$ freezer. Oxygen saturation was measured in the three brine-seawater interfaces. However, methane concentrations were obtained from a previous study (Figure 1) (Schmidt et al., 2003).

\section{DNA EXTRACTION, PYROSEQUENCING, AND CONSTRUCTION OF FUNCTIONAL GENE LIBRARIES}

Total genomic DNA was extracted from each $0.1 \mu \mathrm{m}$ filter applied to the four aforementioned samples, three separate times for each site. Each filter was cut into small square pieces and was incubated with TE buffer (50 mM EDTA + $10 \mathrm{mM}$ Tris) and $2.5 \mathrm{mg} / \mathrm{ml}$ lysozyme at $37^{\circ} \mathrm{C}$ for $2 \mathrm{~h}$. Subsequently, proteinase $\mathrm{K}(200 \mu \mathrm{g} / \mathrm{ml})$ and $1 \%$ SDS were added to the filter pieces, followed by incubation overnight at $55^{\circ} \mathrm{C}$. The Metagenomic DNA Isolation Kit for Water (EPICENTRE Biotechnologies, Madison, WI, USA) was employed to isolate DNA from each treated filter. DNA was quantified via the Picogreen assay using a NANODROP ${ }^{\text {TM }}$ 3300 Fluorospectrometer. The DNA quantities extracted from

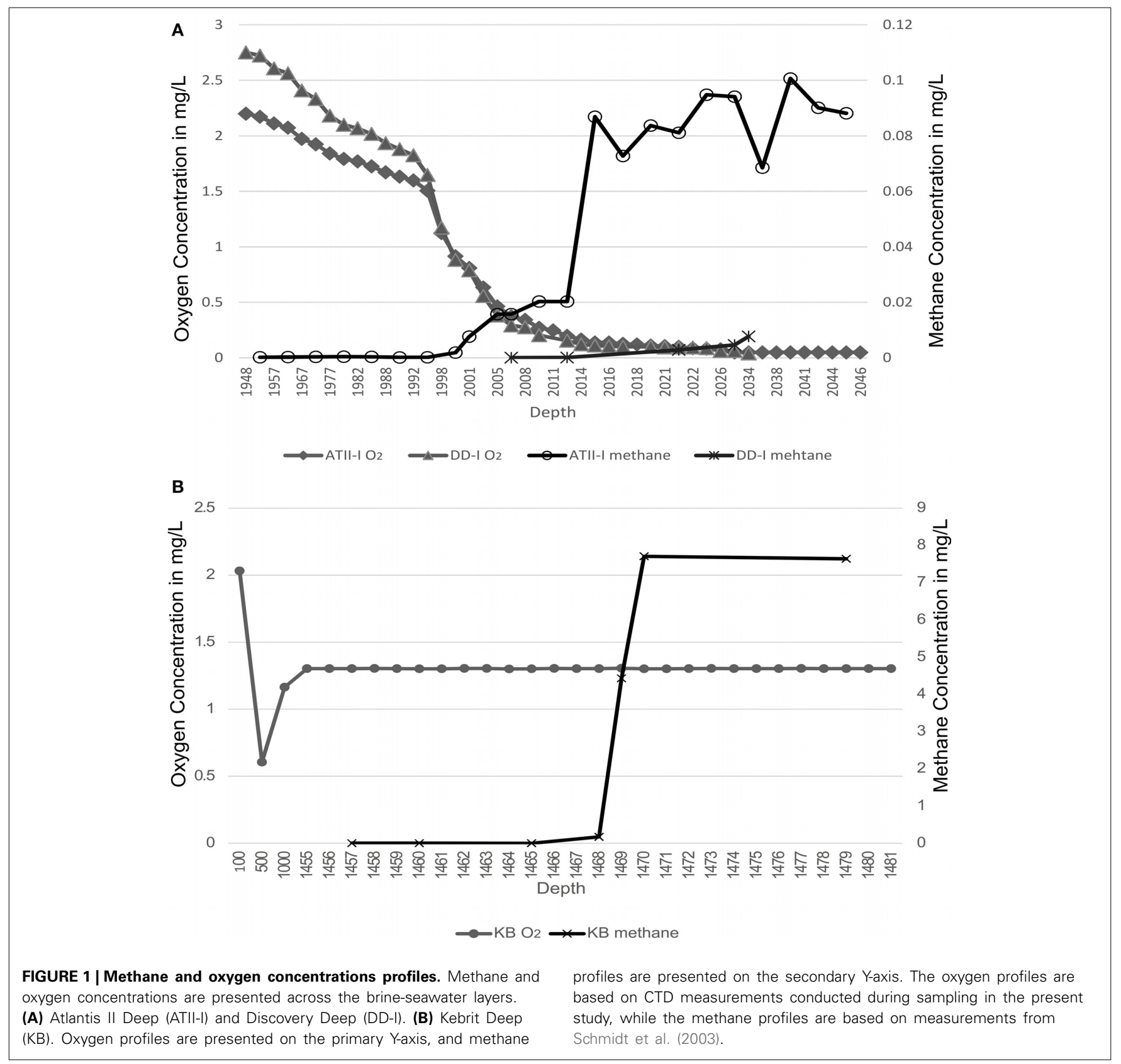


the ATII-I, DD-I, KB-U, and KB-L samples were 5, 5.5, 9.4, and $6.6 \mu \mathrm{g}$, respectively.

Metagenomic libraries for these four different interface layers were constructed as recommended by the GS FLX Roche Titanium library guide, and DNA fragment sizes were selected using the Double SPRI Method (Hawkins et al., 1994). Pyrotag sequence analysis was performed as described in Siam et al. (2012), using universal bacterial primers to amplify the V4-V6 regions of 16S rRNA (Siam et al., 2012). The 16S rRNA pyrosequencing analysis was performed three different times for each sample, and the results were merged. Shotgun sequencing was performed once for each sample. Pyrosequencing of both the $16 \mathrm{~S}$ rRNA amplicons $(486.3 \pm 0.04 \mathrm{bp})$ and metagenomes $(327.13 \pm$ $0.06 \mathrm{bp}$ ) were performed using 454 GS FLX Titanium technology (454 Life Sciences).

pmoA plasmid library construction was performed using the A189f-A682r and the A189f-mb661r primer pairs via the seminested approach, as described by Horz et al. (2005). We were only able to amplify the pmoA gene $(500.4 \pm 2.2 \mathrm{bp})$ from ATIII and KB-U DNA. Approximately $100 \mathrm{ng}$ of template DNA was used. The first round of PCR was performed in triplicate, and the pooled template was used for the second round of PCR (Horz et al., 2005). The gel-extracted PCR products were cloned into the pGEM $^{\circledR}$ - T Easy Vector (Promega, Madison, WI, USA) according to the manufacturer's instructions and transformed into TOP10 E. coli. From the transformed cells, 98 and 96 randomly selected clones from ATII-I and KB-U, respectively, were grown on LB media for DNA extraction. Plasmid DNA extraction was carried out using the R.E.A.L. Prep 96 Plasmid Kit (QIAGEN, Valencia, CA, USA). All of the extracted plasmids were sequenced using a 96-Capillary Sequencer 3730xl DNA Analyzer (Applied Biosystems, Carlsbad, CA, USA). The cloned inserts were amplified using the M13F and M13R sequencing primers (Promega, Madison, WI, USA). Cycle sequencing was conducted in both directions using the BigDye ${ }^{\circledR}$ Terminator v3.1 Kit.

\section{BIOINFORMATICS ANALYSES}

The preprocessing (quality trimming and filtering) of 16S rRNA was performed using the Visualization and Analysis of Microbial Population Structures (VAMPS) website, http://vamps.mbl.edu/ (Sogin et al., 2006; Huse et al., 2014). This procedure was followed by dereplication and chimera checks (both de novo and reference based) using the UCHIME algorithm implemented in USEARCH (Edgar et al., 2011). Rarefaction analysis for $16 \mathrm{~S}$ rRNA pyrotags was conducted using Quantitative Insights Into Microbial Ecology (QIIME) software, with a 99\% similarity threshold (Caporaso et al., 2010). Further alpha diversity analysis measures for the 16S rRNA pyrotags were calculated using QIIME v.1.4. The taxonomic assignments of the $16 \mathrm{~S}$ rRNA pyrotags were determined using the Global Assignment of Sequence Taxonomy pipeline available through VAMPS (Huse et al., 2008). To reveal the $16 \mathrm{~S}$ rRNA pyrotags unique to the interfaces, a local BLASTn search with $97 \%$ coverage and a $97 \%$ identity threshold was performed, aligning the interface layer pyrotags against the ATII water column samples $(50,200,700,1500 \mathrm{~m})$. Then, interface pyrotags that showed a hit among the ATII water column samples were eliminated from the VAMPS taxonomic classification.
Statistical filtering of the taxa identified from the 16S rRNA pyrotags unique to the interfaces was performed using the two-tailed Fisher's exact test (FET) (Fisher, 1970). Taxa lacking statistically significant differences between samples were eliminated using FET. Then, the pyrotags were normalized based on percentages. FET was carried out using R software (http://www.r-project.org/) with a $p$-value threshold $\leq 0.05$ and Bonferroni correction ( $R$ Development Core Team, 2010).

A phylogenetic tree of the $16 \mathrm{~S}$ rRNA sequences was generated using selected operational taxonomic units (OTUs) from the pyrotags from the ATII-I, KB-U, and KB-L libraries, in addition to selected SILVA nr (release 115) reference sequences (Quast et al., 2013). The high-quality pyrotags were downloaded from the VAMPS web server and clustered using USEARCH with a 0.99 similarity threshold (Edgar, 2010). OTUs and reference sequence pairs were selected from SILVA nr based on annotation by BLASTn, where only hits to methane-oxidizing and methylotrophic species with a percent identity $>95 \%$ and an $E<1 \mathrm{e}-5$ were considered. Multiple sequence alignment was performed with MUSCLE (Edgar, 2004). FastTree was employed to generate the final tree using the GTR substitution model and 100 bootstrap replicates (Price et al., 2009).

Preprocessing of $p m o A$ was performed via (1) trimming vector and low-quality bases (sequences with a quality score $\leq 30$ were eliminated) using CodonCode Aligner software (CodonCode Corporation, Dedham, MA, USA), (2) Chimera checks using the UCHIME algorithm implemented in USEARCH (Edgar et al., 2011) (both de novo and with the reference-based approach) and (3) ORF calling using FragGeneScan (Rho et al., 2010). Then, the sequences were confirmed by BLASTx searches against the NCBI nr database dated 12 2013. Of the 98 ATII-I and 96 KBU sequences only 59 and 80 , respectively, were considered good quality DNA sequences and were used for alpha diversity, taxonomic and phylogenetic analyses. The alpha diversity of the pmoA libraries was determined using MOTHUR v.1.18.1 (Schloss et al., 2009). A distance threshold of 0.1 ( $90 \%$ nucleotide sequence similarity) was employed (Heyer et al., 2002; Wasmund et al., 2009). The distance matrix was based on multiple sequence alignments generated with the Multiple Sequence Comparison by Log-Expectation (MUSCLE) program (Edgar, 2004). A phylogenetic tree of the pmoA sequences was generated using reference sequences recruited by a local BLASTx search (maximum E-value of $1 \mathrm{e}-5$ and 100 hits/sequence) was carried out on the $p m o A$ clonal inserts against the GenBank non-redundant database (December 2013) to identify the most closely related cultured and uncultured methanotrophs for each sequence; other reference sequences of cultured methanotrophs and $p x m A$ genes were also included (Tavormina et al., 2011). The pmoA DNA sequences from ATII-I and KB-U were first clustered into OTUs with a distance threshold of 0.1 using USEARCH (Schloss et al., 2009). The deduced protein sequences of the pmoA OTUs and selected references were employed in the construction of the phylogenetic tree. Multiple sequence alignment was performed using MUSCLE (Edgar, 2004). A maximum likelihood phylogenetic tree was generated using PhyML, with 5 random seeds AND confidence values calculated using 100 bootstrap replicates (Stamatakis, 2006; Guindon et al., 2010). The LG substitution model and a 
gamma distribution were utilized. FigTree (http://tree.bio.ed.ac. uk/software/figtree/), and Archaeopteryx was employed for tree editing (Han and Zmasek, 2009).

Metagenomic reads were deposited in the Meta-Genome Rapid Annotation using Subsystem Technology MG-RASTCLOUD (version 3) server (Meyer et al., 2008). A protein-based phylogenetic analysis was performed through MG-RAST server sequence similarity searches against the M5NR database, with a maximum $E$-value of $1 \mathrm{e}-5$, a minimum identity of $50 \%$ and a minimum alignment length of 20 aa (Meyer et al., 2008). Similar to the pyrotag analyses, statistical filtering of the metagenomic reads was performed using FET, and the reads were then normalized based on percentages.

Recruitment to Kyoto Encyclopedia of Genes and Genomes (KEGG) categories was performed using BLASTx, employing the reads from each of the brine sequence sets as queries against a modified KEGG database using an E-value of 1e-5. A nonmetric multidimensional scaling (NMDS) analysis of the reads recruited to the methane metabolism KEGG pathway was performed using the $\mathrm{R}$ package vegan ( $\mathrm{R}$ Development Core Team, 2010; Oksanen et al., 2013). Standardization and dissimilarity measures were applied as previously described in Anderson et al. (2006). The matrix was normalized to the total count of recruited reads, scaled and log transformed to base 2 , and the modified Gower index was employed as a dissimilarity measure (Anderson et al., 2006). An ordination in 2 NMDS dimensions and 3D space was performed using the NMDS function in the vegan package (Oksanen et al., 2013). KEGG orthologous groups were clustered using hierarchical clustering (Suzuki and Shimodaira, 2006). The classification of KEGG orthologous groups into clusters represented in the NMDS was performed based on the modified Gower distance matrix, the complete linkage method and 1000 bootstrap replicates using the pvclust package (Suzuki and Shimodaira, 2006). The cluster solution was selected using the silhouette criterion (Kaufman and Rousseeuw, 1990; Maechler et al., 2013). A heat map representation was generated using the gplots package (Warnes et al., 2011) via hierarchical clustering with a Spearman correlation distance matrix, and the complete linkage clustering method was applied to normalized log-transformed values.

The obtained $p m o A$ sequences were deposited in GenBank under accession numbers KJ175561-KJ175699. The direct DNA shotgun pyrosequences and 16S rRNA pyrotags were deposited in the Short Read Archive (SRA) database, listed under BioProject PRJNA219363.

\section{RESULTS}

\section{$16 S$ rRNA, pmoA AND SHOTGUN METAGENOMIC LIBRARIES GENERATED FROM RED SEA BRINE-SEAWATER INTERFACES}

More than 60500 bacterial 16S rRNA pyrotags were generated from ATII-I, DD-I, KB-U and KB-L. Taxonomic assignment of OTUs to major bacterial groups led to the identification of 97, 81,74 , and $58 \%$ of the bacterial OTUs in ATII-I, DD-I, KB-L, and $\mathrm{KB}-\mathrm{U}$, respectively (Table 2 ). The greatest number of OTUs not assigned to known bacterial taxa was observed in the KB$\mathrm{U}$ library (Table 2). The difference between the total number of pyrotags and bacterial reads (Table 2) represents non-specific tags that are taxonomically assigned to an archaeal/eukaryal origin. The gene encoding the structural polypeptide $\mathrm{pMMO}$ $(p m o A)$ was only amplified from the ATII-I and KB-U samples. Following the elimination of low-quality reads, a total of 59 and 80 sequences were recovered from the ATII-I and KB-U libraries, respectively. Additionally, $\sim 4$ million metagenomic (454) reads were generated from the four different Red Sea brine-seawater interface layers. The percentage of metagenomic (454) reads that were phylogenetically assigned to a known bacterial origin based on protein sequences varied in the different samples tested; the highest number of bacterial reads was identified in $\mathrm{KB}-\mathrm{U}$ $(\sim 50 \%)$ and the lowest in DD-I $(\sim 17 \%)$. The greatest numbers of metagenomic (454) reads without a match to a public database $(\sim 75 \%)$ were observed in the ATII-I and DD-I layers (data not shown).

\section{BACTERIAL COMMUNITIES IN THE BRINE-SEAWATER INTERFACE LAYERS}

Taxonomic assignment of OTUs to the major bacterial groups was performed for the $16 \mathrm{~s}$ rRNA pyrotag libraries. We eliminated $16 \mathrm{~s}$ rRNA pyrotags found in the Atlantis II overlying water column by subtracting similar reads from the brine-seawater interface pyrotags (described in the Materials and Methods). Thus, we excluded pyrotags that were potentially shared with the overlying water column. It has been shown that the overlying water columns at ATII and DD are relatively homogenous at similar depths (Qian et al., 2011), and we therefore utilized data from the ATII overlying water column in our analysis. The number of unique brineseawater interface pyrotags were 13357, 3407, 8234, and 10981 for ATII-I, DD-I, KB-U, and KB-L, respectively (Supplementary Table 1). Alpha diversity analyses of the $16 \mathrm{~S}$ rRNA pyrotags (from the entire bacterial community) indicated that the $\mathrm{KB}$ interface

\begin{tabular}{llccc} 
Table 2 | Description of the different libraries generated in this study. \\
\hline Samples & Samples & $\begin{array}{c}\text { 16S rDNA } \\
\text { Reads \#/\% }\end{array}$ & $\begin{array}{c}\text { pmoA } \\
\text { Reads \#/\% }\end{array}$ & $\begin{array}{c}\mathbf{4 5 4}^{* *} \\
\text { Reads \#/\% }\end{array}$ \\
\hline Bacteria & AT II-I & $16104 / 96.9$ & $59 / 100$ & $119158 / 19.7$ \\
& DD-I & $13376 / 81.3$ & NA & $115943 / 17.6$ \\
& KB-U & $8069 / 58$ & $80 / 100$ & $707139 / 49.9$ \\
& KB-L & $9942 / 73.5$ & NA & $451616 / 32.9$ \\
\hline Total & AT II-I & 16618 & 59 & 604000 \\
& DD-I & 16457 & NA & 658619 \\
& KB-U & 13904 & 80 & 1417636 \\
& KB-L & 13523 & NA & 1370213 \\
\hline Unknown* & AT II-I & $4 / 0.02$ & NA & $23299 / 3.9$ \\
& DD-I & $755 / 4.6$ & NA & $27301 / 4.1$ \\
& KB-U & $689 / 4.9$ & NA & $120459 / 8.5$ \\
& KB-L & $501 / 3.7$ & NA & $79137 / 5.8$
\end{tabular}

* Unknown represents the number of reads not assigned to any known Taxa.

NA, Not Available.

**The table presents only reads assigned to a bacterial origin (including unknown). The 454 archaeal, eukaryotic and reads showing no hits to public databases are not presented and represent the remaining percentage of reads. 
layers (both lower and upper) showed the highest diversity, followed by DD-I and, finally, ATII-I (Supplementary Table 2). In the following order, the ATII-I unique OTUs were dominated by unknown phylotypes of Phyllobacterium (Phyllobacteriaceae) and Enhydrobacter (Moraxellaceae), unknown genera of SAR406 and Phyllobacterium myrsinacearum (order: Rhizobiales) (Figure 2, Supplementary Table 3), while unknown phylotypes of Leucothrix (order: Thiotrichales), Scalindua (order: Planctomycetales), and Mariprofundus (order: Mariprofundales) and an unknown class of OD1 represented less abundant and unique ATII-I OTUs (Supplementary Table 3). Unknown classes of OD1 and OP3 dominated the unique KB-L OTUs (Figure 2, Supplementary Table 3). The less abundant and unique KBL OTUs included unknown genera of Desulfobacteraceae (order: Desulfobacterales), an unknown phylotype of Sulfurovum (order: Campylobacterales), and unknown classes of WS3, OP1, and TM6, along with an unknown order of Spirochaetes (Supplementary Table 3). The unique KB-U OTUs were dominated by unknown genera of SAR406, unknown phylotypes of Scalindua, Nitrospira (order: Nitrospirales), and Methylobacter lutues (order: Methylococcales), and an unknown class of OD1 (Figure 2, Supplementary Table 3). The less abundant and unique KB-U OTUs were Methylophaga aminisulfidivorans (order: Thiotrichales), unknown phylotypes of Methylobacter and Iamia (order: Acidimicrobiales), unknown genera of Rhodospirillaceae (order: Rhodospirillales) and an unknown family of SAR324 (Supplementary Table 3). An unknown phylotype of Pelagibacter (order: Rickettsiales) dominated the DD-I unique OTUs (Figure 2, Supplementary Table 3), while the less abundant and unique OTUs found in DD-I consisted of unknown phylotypes of Myxococcus (order: Myxococcales) (Supplementary Table 3).

\section{AEROBIC METHANOTROPHIC COMMUNITIES AT THE BRINE-SEAWATER INTERFACE IDENTIFIED BASED ON 16S rRNA PYROTAGS AND SHOTGUN PYROSEOUENCING METAGENOMIC ANALYSES}

The VAMPS taxonomic classification (Table 3 and Supplemental Table 3) and the phylogenetic clustering of 16S rRNA sequences against methanotroph and methylotrophic $16 \mathrm{~S}$ rRNA sequences

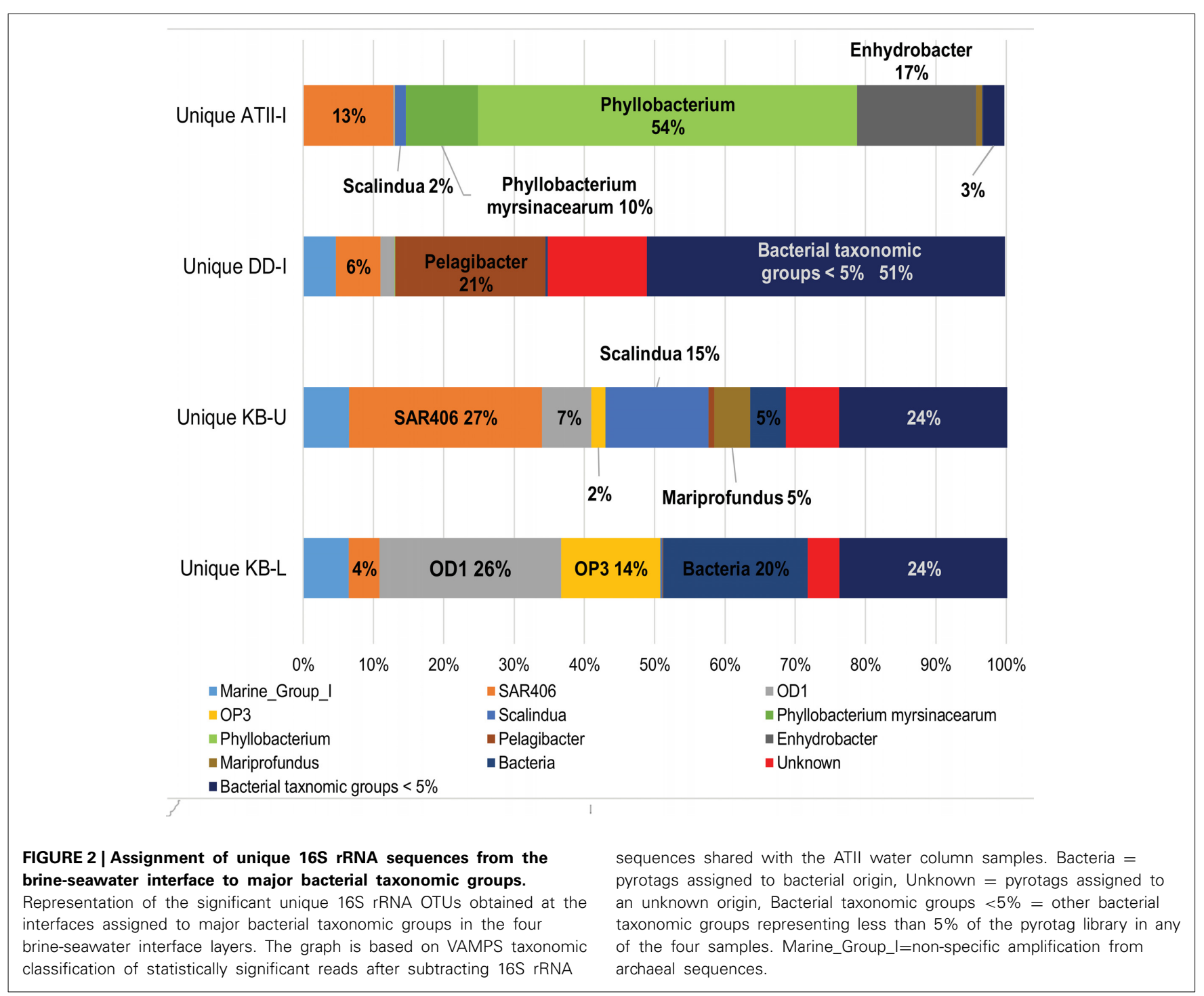




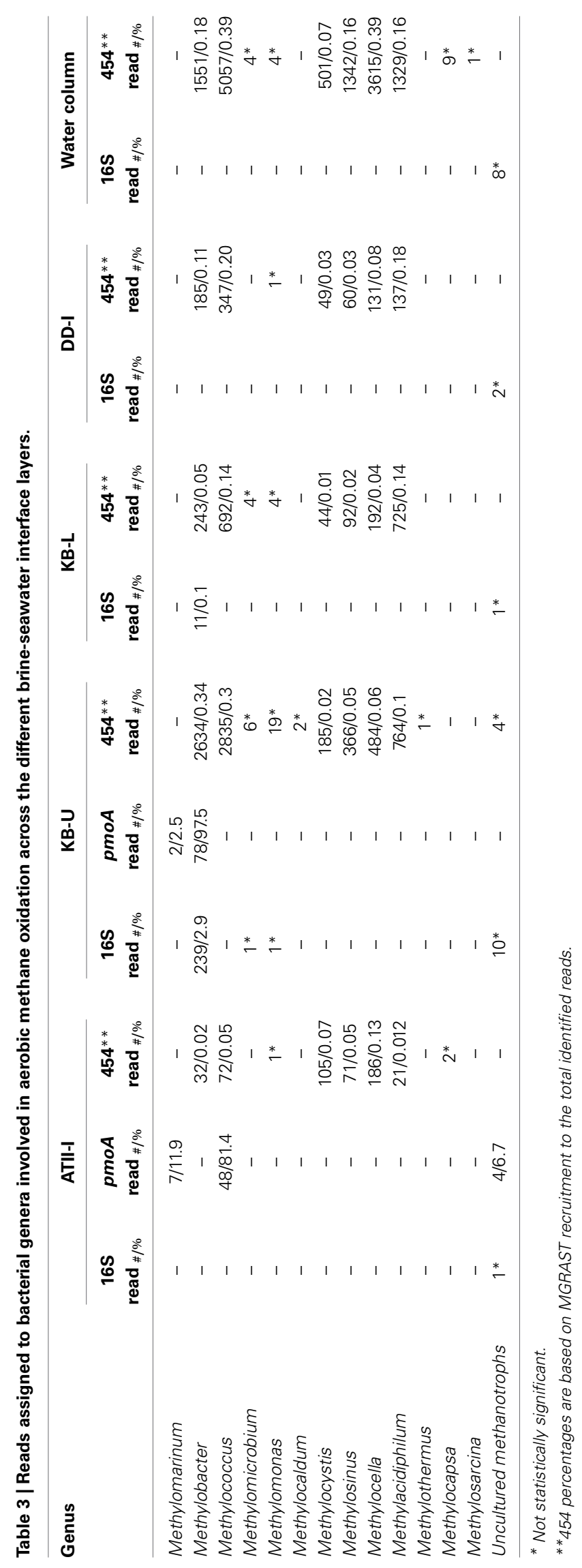

retrieved from the SILVA nr database (Figure 3A) were used to assess the phylogeny of the known aerobic methanotrophs inhabiting the brine-seawater interface layers (Hanson and Hanson, 1996; Dunfield et al., 2007; Pol et al., 2007; Islam et al., 2008; Murrell, 2010; Qian et al., 2011; Siam et al., 2012). The results of the rarefaction analysis of the $16 \mathrm{~S}$ rRNA showed that only ATII-I has reached saturation (Figure 3B).

VAMPS taxonomic classification identified 250 statistically significant bacterial $16 \mathrm{~S}$ rRNA pyrotags assigned to the Methylococcaceae family in the Kebrit interface layers (Table 3). Among the 16S rRNA tags, $2.9 \%$ (239 reads) and 0.1\% (11 reads) of the $16 \mathrm{~S}$ rRNA tags from KB-U and KB-L, respectively, were taxonomically assigned to the genus Methylobacter (Table 3). The ATII-I and DD-I OTUs represented $8 \%$ (4\% each) of the 25 total methylotrophic Red Sea interface OTUs (Figure 3A), while the KB-L and KB-U OTUs represented 20 and $72 \%$ of the total number, respectively (Figure 3A).

Phylogenetically, 18 OTUs from KB-U were related to two major groups: type I methanotrophs and methylotrophic bacteria (Figure 3A). Seven of the KB-U OTUs were found to be related to the methylotrophic bacteria of the Methylophaga genus. The greatest number of KB-U OTUs (9) were phylogenetically related to several marine methanotrophs, with the genus Methylobacter being the most closely related cultured methanotroph (Figure 3A). Moreover, two OTUs represented an out-group of the Methylobacter clade.

The KB-L interface possessed five OTUs that were phylogenetically related to methanotrophs and methylotrophs. Two OTUs were related to the methylotrophic bacteria of the Methylophaga genus, while two were related to several marine methanotrophs, with the genus Methylobacter representing the most closely related cultured group of methanotrophs (Figure 3A). One OTU was clustered with $16 \mathrm{~S}$ rRNA sequences from the methylotroph Methylobacterium ( $\alpha$-proteobacteria).

For ATII-I, only one 16S rRNA OTU was phylogenetically assigned to Methylobacterium, while DD-I presented only one $16 \mathrm{~S}$ rRNA OTU that was phylogenetically related to Methylophaga.

Reads assigned to aerobic methanotrophs were identified in the four libraries using sequence similarity searches of $\sim 4$ million metagenomic (454) reads. Similar to the $16 \mathrm{~S}$ rRNA analyses, the pyrosequencing read rarefaction analyses showed that only ATII-I has reached saturation (data not shown). The percentages of reads corresponding to aerobic methanotrophs in the different libraries were quite low $(\sim 0.5 \%)$, though the highest percentage assigned to the Methylobacter genus was found in KB-U $(\sim 0.3 \%)$ (Table 3). Reads assigned to type II methanotrophs were only present in the four shotgun pyrosequencing libraries.

\section{AEROBIC METHANOTROPHIC COMMUNITIES AT THE BRINE-SEAWATER INTERFACE BASED ON /pmoA PHYLOGENETIC ANALYSES}

We further investigated the aerobic methanotrophic communities using clone libraries of the particulate methane monooxygenase gene $(p m o A)$. We were only successful in amplifying $p m o A$ from ATII-I and KB-U. A total of 139 clones were sequenced for the two samples studied, with 59 clones from ATII-I and 80 from KB-U being identified as pmoA. Rarefaction analysis of the 


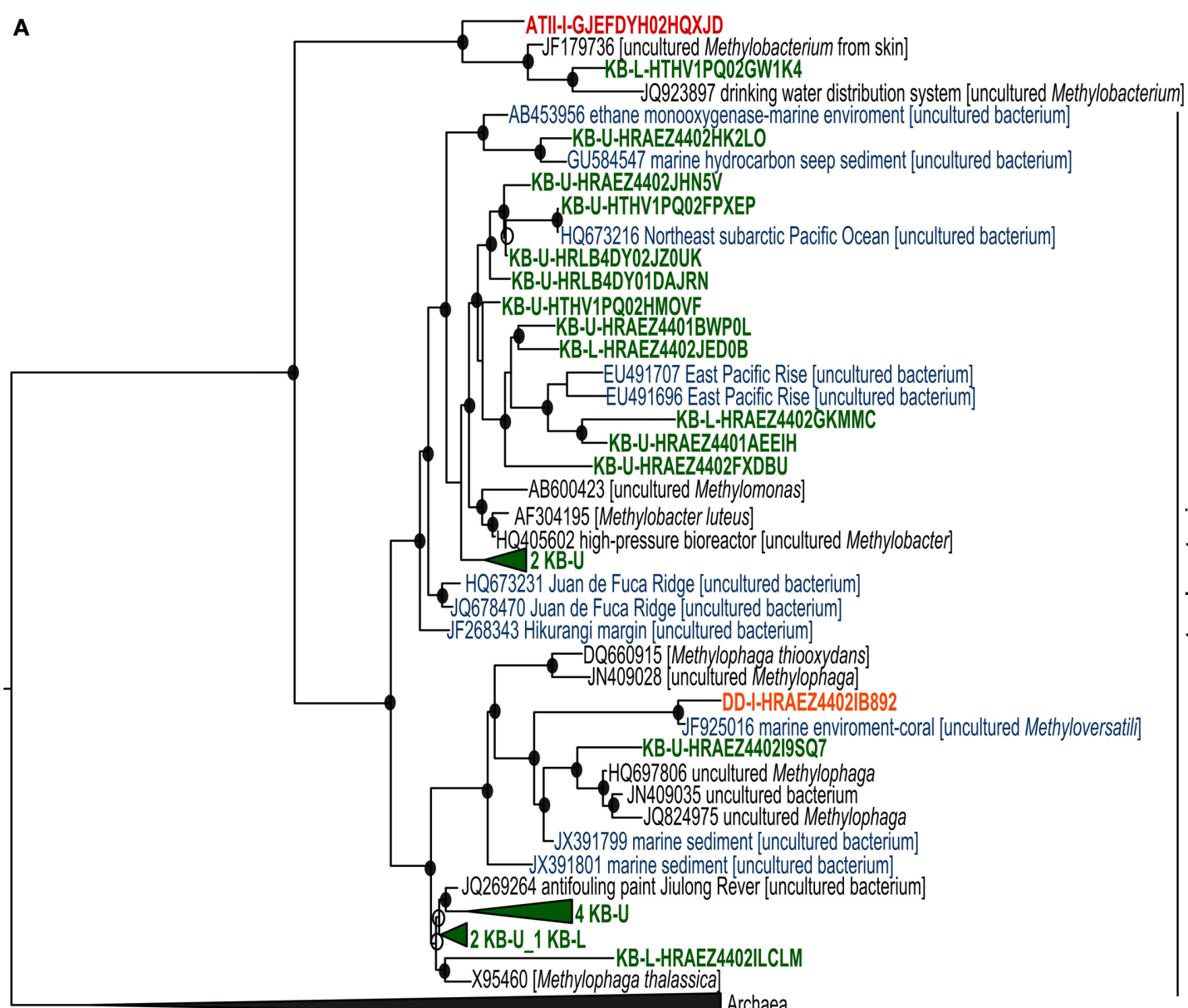

B

$\overline{0.1}$

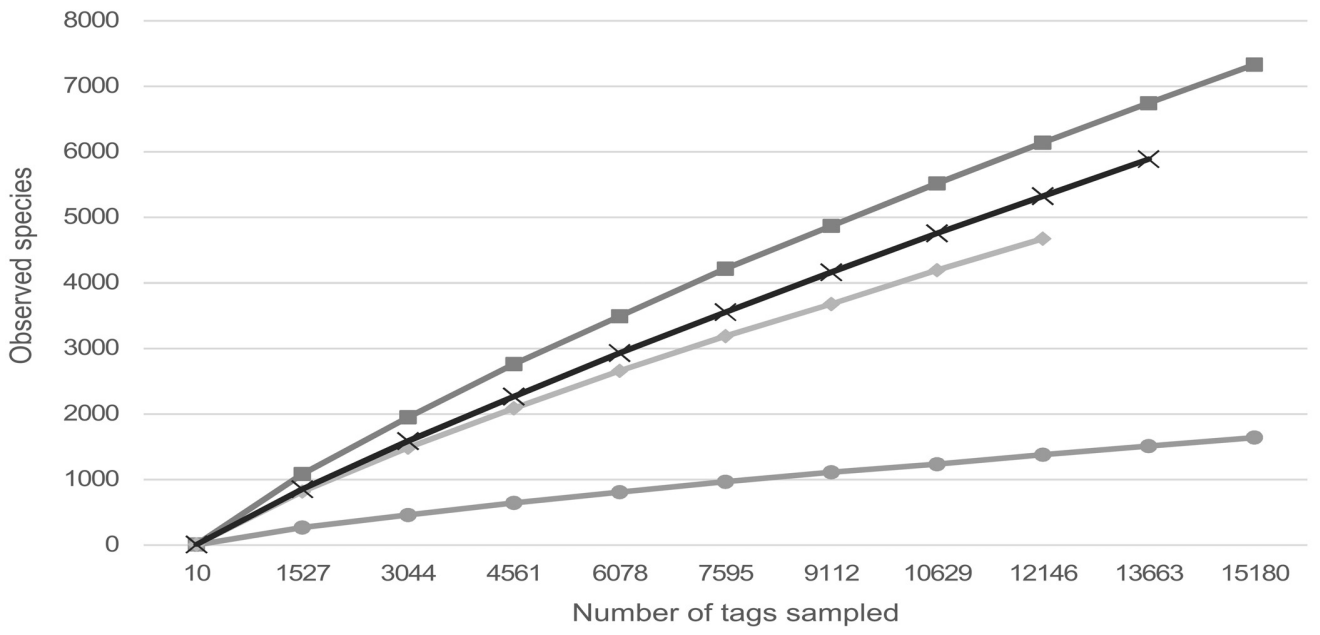

$\longrightarrow$ DD-I $\longrightarrow$ ATII-I $\leadsto$ KB-L $\longleftrightarrow$ KB-U

FIGURE 3 | 16S rRNA phylogenetic tree and species richness of aerobic methanotrophs. (A) Nucleotide phylogeny of the predicted 16S rRNA pyrotags generated from ATII-I (red), DD-I (orange) and KB-U/KB-L (green). Blue sequences represent 16S rRNA derived from marine environments. Red Sea brine pool OTUs based on $99 \%$ sequence identity were compared with SILVA $16 S$ rRNA. The tree was generated using an 1891-bp alignment. The numbers of sequences collapsed in the selected node are indicated adjacent to the sample name. The trees were calculated using the maximum-likelihood approach with 100 bootstrap resampling. Bootstrap values $\geq 50 \%$ are depicted as open circles and those $\geq 70 \%$ with closed circles. The scale bar represents $10 \%$ estimated sequence divergence. (B) Species richness in the ATII-I, DD-I, KB-U and KB-L brine-seawater interface layers based on $16 \mathrm{~S}$ rRNA pyrotag rarefaction curve analysis. Phylotypes were generated based on a distance threshold of 0.01 . 
$p m o A$ clone libraries indicated that sufficient numbers of $p m o A$ genes were amplified from the aerobic methanotrophic community (Figure 4B). In contrast to the alpha-diversity 16S rRNA analyses, the $p m o A$ aerobic methanotrophic communities showed more diversity in ATII-I than KB-U (Supplementary Table 2). Six pmoA OTUs were identified in ATII-I, while only two were identified in KB-U (Table 3). The sequences were aligned to the GenBank database, and similarity searches between the sequences were conducted using BLASTx. A phylogenetic tree was generated using the maximum likelihood method. Both ATII-I and KB-U clones were phylogenetically classified as type I methanotrophs $\gamma$-proteobacteria).

The obtained $p m o A$ sequences were divided into six distinct clusters; four were unique to ATII-I, and two were unique to $\mathrm{KB}-\mathrm{U}$. The clusters are presented and numbered in descending order in the tree (Figure 4A). In the ATII-I pmoA library, the majority $(\sim 81 \%)$ (ATII-I cluster 3 and 4 ) of the $p m o A$ clones appeared to be related to different uncultured methanotrophs (Figure 4A, Table 3 and Supplementary Table 4), with the genus Methylococcus (Table 3) and the species Methylococcus capsulatus (Supplementary Table 4) representing the most closely related cultured methanotrophs. Of the ATII-I pmoA clones (ATII-I cluster 1 ), $12 \%$ were closely related to the newly discovered aerobic methanotroph Methylomarinum vadi, while 7\% (ATII-I cluster 4) were not assigned to any cultured methanotrophs (Figure 4A, Table 3 and Supplementary Table 4). Phylogenetically, two OTUs (ATII-I cluster 2) of the six clustered with uncultured marine methanotrophs identified from water and sediment samples from methane seeps. This cluster showed the Methylococcus genus as the most closely related group of cultured methanotrophs (Figure 4A). One OTU (ATII-I cluster 3) represented an outgroup of the marine methanotroph clade and was related to an uncultured bacterium from landfill soil (Figure 4A). Seven reads (one OTU-ATII-I cluster 1) from the ATII-I library were phylogenetically closely related to the newly discovered genus Methylomarinum (species Methylomarinum vadi) (Hirayama et al., 2013). Interestingly, of the 59 clones that were related to several uncultured and cultured methanotrophs, our sequence similarity searches showed 4 highly divergent clones (two OTUsATII-I cluster 4) presenting less than $70 \%$ identity to any known pmoA sequence (Figure 4A and Supplementary Table 4). These OTUs were represented in the tree as a divergent clade of alkane monooxygenases. The alkane monooxygenases and partial pxmA genes were shown in the tree as an out-group of both Type I and Type II methanotrophs (Figure 4A).

In the KB-U library, 78 clones/one OTU-KB-U cluster 2 $(97.5 \%)$ were closely related to the genus Methylobacter according to sequence similarity searches, while phylogenetically, they showed an unclear affiliation with the Methylobacter clade. The other KB-U OTU (KB-U cluster 1) represents an out-group of the Methylomarinum/Methylomonas clade (Figure 4A).

\section{METHANE METABOLIC PROFILES IN THE BRINE-SEAWATER INTERFACE LAYERS BASED ON SHOTGUN PYROSEQUENCING METAGENOMIC READS}

To obtain a better understanding of the methane metabolism occurring in the three brine-seawater interfaces, metagenomic
(454) reads were mined for enzymes involved in the methane pathway within the KEGG database. We present an NMDS analysis of putative enzymes involved in methane metabolism in the interface brine samples in both 3D and 2D (Figure 5). The NMDS analysis presented in $3 \mathrm{D}$ converged with a stress value of $\approx 0.054$, whereas the $2 \mathrm{D}$ presentation converged with a stress value of $\approx 0.098$. The ordination of KEGG orthologous groups in the NMDS showed two different clusters. Cluster 1 included KB-U and KB-L samples, with 95\% confidence. ATII-I and DD-I did not group together or with the KB samples. However, ATII-I was markedly dissimilar from the other analyzed samples. Of 133 enzymes involved in methane metabolism identified in our samples, only 37 were associated with aerobic methane oxidation. Those 37 enzymes included major enzymes involved in methane oxidation and formaldehyde assimilation in aerobic methanotrophs. The key enzyme methane monooxygenase was represented by 5 KOs (KEGG Orthologs): K10944 (pMMO subunit A), K10945 (pMMO subunit B), K10946 (pMMO subunit $\mathrm{C}$ ), and K16158 (sMMO subunit A), which were mainly present in $\mathrm{KB}-\mathrm{U}$, while $\mathrm{K} 16161$ (sMMO subunit C) was present in all layers, showing higher abundance in KB-U (Table 4, Supplementary Table 5). The other identified enzymes involved in the oxidation of methane to carbon dioxide were formaldehyde dehydrogenase and formate dehydrogenase, which were detected in DD-I and all layers, respectively, while methanol/alcohol dehydrogenase was absent. Formaldehyde dehydrogenase (K00148) was only found in DD-I. Formate dehydrogenase (K00122, K00123, K00124, K00125, K00127, K05299, K08348, and K15022) was mainly detected in Kebrit layers and was found at a low abundance in DD-I and ATI-II (Supplementary Figure 1 and Supplementary Table 5). All of the known enzymes involved in methane oxidation via the tetrahydromethanopterin pathway were detected in both Kebrit layers and ATII-I, but at a lower abundance. In DD-I, the enzyme methylenetetrahydromethanopterin dehydrogenase was not detected (Supplementary Figure 1 and Supplementary Table 5).

Major enzymes known to be involved in formaldehyde assimilation through the serine pathway were identified mainly in $\mathrm{KB}-\mathrm{U}$ and at a lower abundance in KB-L, DD-I, and ATII-I, with the exception of glycerate kinase. Only two enzymes involved in the other formaldehyde assimilation pathway (the ribulose monophosphate cycle) were identified, mainly in the Kebrit Interface: 3-hexulose-6-phosphate synthase (K08093) and 6-phospho-3-hexuloisomerase (K08094 and K13831) (Supplementary Figure 1 and Supplementary Table 5).

\section{DISCUSSION}

This study is the first to investigate and compare the aerobic methane-oxidizing communities present at three Red Sea brine-seawater interfaces, at the Atlantis II, Discovery and Kebrit Deeps. Serial water filtration of the brine-seawater interface samples allowed us to focus on free-living prokaryotes. The density gradient created at the brine-seawater interface causes organic and inorganic matter from the overlying seawater to be trapped (Hartmann et al., 1998; Schmidt et al., 2003). Therefore, the microbial communities attached to these particles as well as those living in symbiosis with eukaryotic microorganisms are likely to 


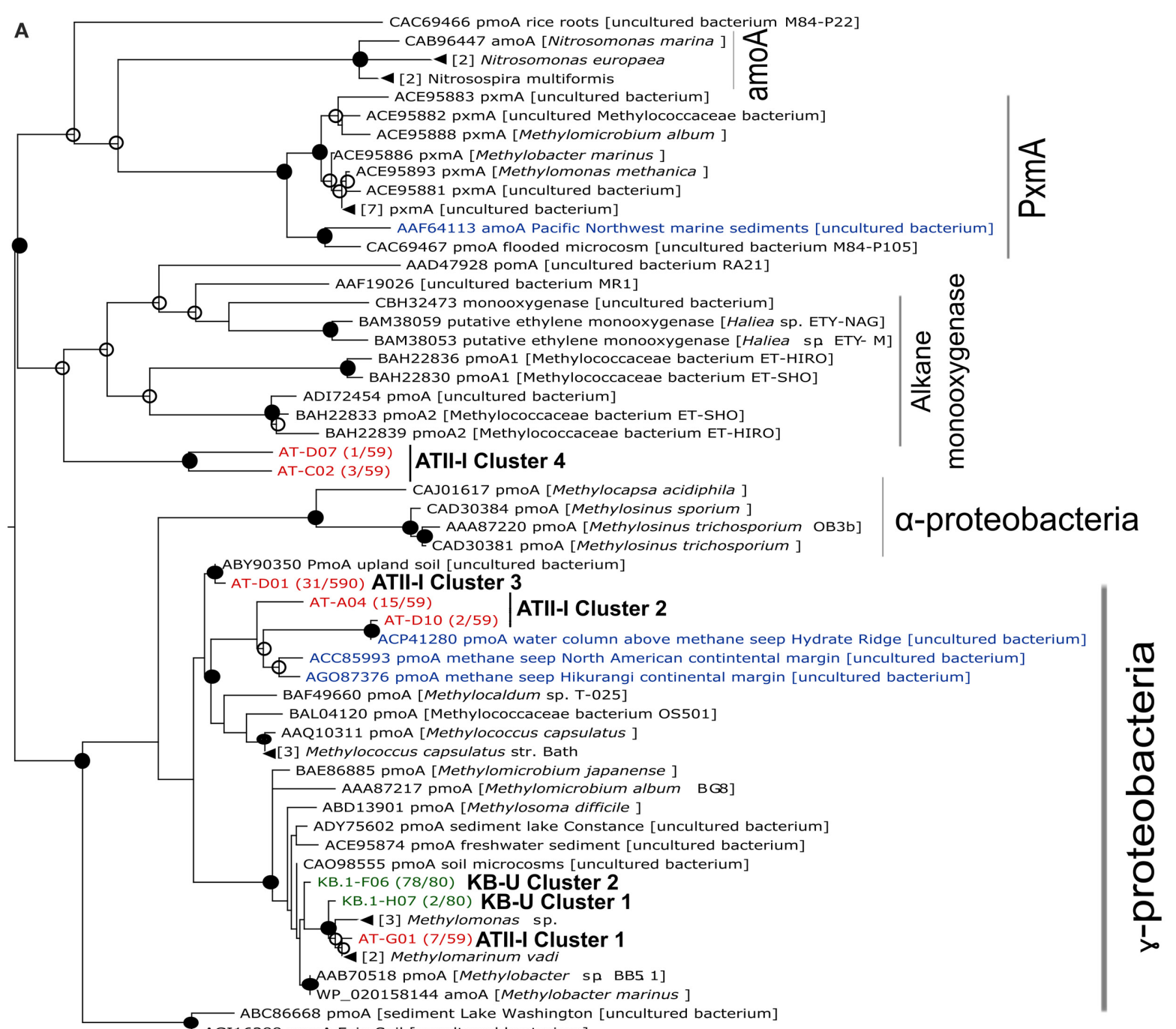

B

AGI16288 pmoA Fein Soil [uncultured bacterium]

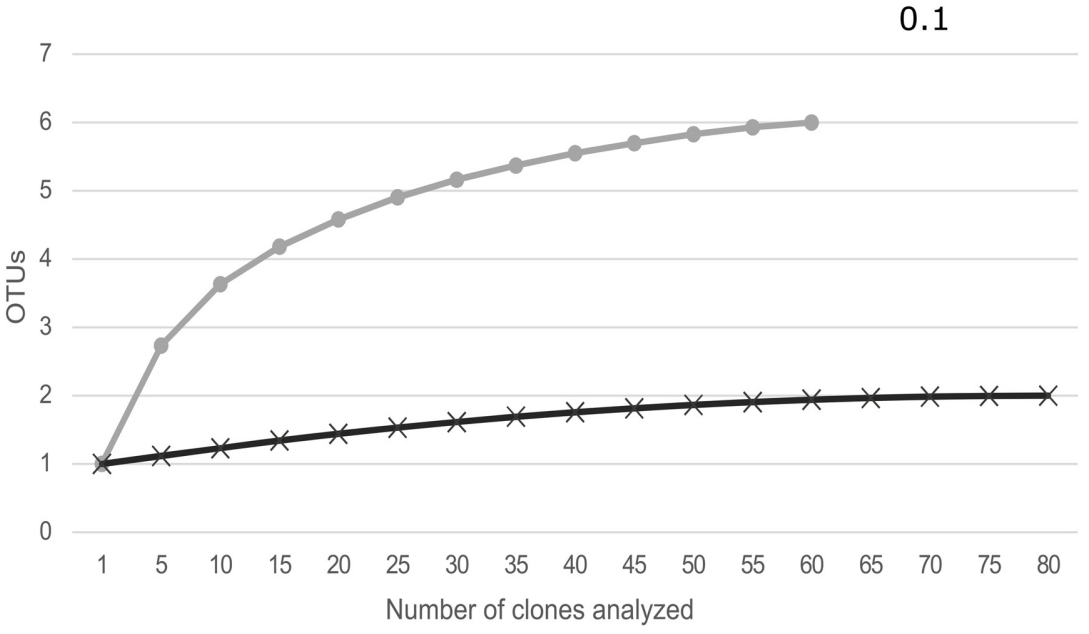

$\rightarrow$ ATII-I $\leftarrow$ KB-U

FIGURE 4 | pmoA phylogenetic tree and species richness of aerobic methanotrophs. (A) Deduced amino acid phylogeny of predicted pmoA sequences amplified from ATII-I (6 OTUs-red) and KB-U (2 OTUs-green) based on $90 \%$ nucleotide sequence identity. The Red Sea brine pool OTUs were compared with deduced amino acid sequences for pmoA derived from other marine environments (blue), soil and cultured methanotrophs. The number between parentheses, following the sequence name, represents the

(Continued) 


\section{FIGURE 4 | Continued}

number of sequences within the library that belong to the represented OTUs. The tree was generated using 168 aa. The numbers of sequences collapsed in the selected node are indicated adjacent to the sample name. The tree was calculated using the maximum-likelihood approach with 100 bootstrap replicates. Percentages greater than $50 \%$ of bootstrap resampling are indicated with an open circle and those greater than $70 \%$ with a closed circle near the nodes. The scale bar represents $10 \%$ estimated sequence divergence. (B) Species richness in the Atlantis II Deep and Kebrit Deep brine-seawater interphase layers based on $p m o A$ clone library rarefaction curve analysis. Phylotypes were generated based on a distance threshold of 0.1 .

Table 4 | Comparison of the sMMO and pMMO reads obtained from the brine-seawater interfaces.

\begin{tabular}{lccccc}
\hline Sample description & Sample depth & Oxygen concentration & Methane concentration* & $\begin{array}{c}\text { sMMO } \\
\mathbf{4 5 4} \text { reads }\end{array}$ & $\begin{array}{c}\text { pMMO } \\
\mathbf{4 5 4} \text { reads } \\
\text { clones }\end{array}$ \\
\hline DD-I & $2026-2042 \mathrm{~m}$ & $0.06-0.04 \mathrm{mg} / \mathrm{L}$ & $0.005-0.008 \mathrm{mg} / \mathrm{L}$ & 9 & 0 \\
ATII-I & $1996-2025 \mathrm{~m}$ & $1.5-0.8 \mathrm{mg} / \mathrm{L}$ & $0.0002-0.09 \mathrm{mg} / \mathrm{L}$ & 8 & 0 \\
KB-L & $1469 \mathrm{~m}$ & $1.31 \mathrm{mg} / \mathrm{L}$ & $4.43 \mathrm{mg} / \mathrm{L}$ & 10 & 0 \\
KB-U & $1468 \mathrm{~m}$ & $1.30 \mathrm{mg} / \mathrm{L}$ & $0.17 \mathrm{mg} / \mathrm{L}$ & 30 & 9 \\
\hline
\end{tabular}

${ }^{*}$ Methane concentration is based on Schmidt et al. (2003).

have been excluded from our study due to the applied serial filtration method. Samples of 120 liters collected twice from all sites, with the exception of KB-U, were filtered through separate filters. The different free bacterial communities involved in methane oxidation were assessed using three different approaches: metagenomic (454) libraries, 16S rRNA pyrotags and phylogenetic analysis of $p m o A$ sequences.

The four different brine-seawater interface layers exhibited diverse bacterial communities. Moreover, each brine-seawater interface exhibited unique dominant taxa. ATII-I was dominated by the genera Phyllobacterium (order: Rhizobiales) and Enhydrobacter (order: Pseudomonadales). Phyllobacterium species are known to be involved in aromatic hydrocarbon degradation and have been identified in different marine ecosystems (von der Weid et al., 2008; Shao et al., 2010). This might explain the dominance of Phyllobacterium in ATII-I, due to being a hydrocarbon-rich layer (Burke et al., 1981; Faber et al., 1998; Schmidt et al., 2003). The Kebrit brine-seawater interface layers (KB-U and KB-L) were mainly dominated by the marine Candidatus taxa OP3 and SAR406 (Gordon and Giovannoni, 1996; Glockner et al., 2010; Kumar and Saravanan, 2010). The Candidatus OD1 phylum (dominant in KB-L) is known to occur in marine environments characterized by notable concentrations of sulfur compounds (Harris et al., 2004). The dominance of the marine ammonium oxidizer Scalindua in the KB-U layer can be explained by the presence of a high hydrogen sulfide concentration favoring the sulfur reduction of Planctomycetes (Elshahed et al., 2007). The most dominant bacteria in DD-I belonged the ubiquitous marine bacterial genus Pelagibacter (Morris et al., 2002; Rappe et al., 2002).

The Atlantis II Deep is considered to be the largest, hottest, and saltiest pool in the Red Sea and is characterized by particularly high concentrations of heavy metals relative to other brine pools (Antunes et al., 2011b). Studies examining hydrocarbon concentrations and stable carbon isotopes have provided evidence of methane oxidation at the so-called "anoxic (brine)oxic (seawater) boundary" (Schmidt et al., 2003), or the interface (Faber et al., 1998; Hartmann et al., 1998; Schmidt et al., 2003).
The present study relies on a previously recorded methane stable isotope ratio obtained in 1997 (Schmidt et al., 2003), which is a limitation of our study, as we cannot correlate the abundance and diversity of aerobic methanotrophs with current methane levels. Potential methane-producing Archaea have been identified in the brine pool (Bougouffa et al., 2013) and in different sediment subsections of the Atlantis II Deep (Siam et al., 2012). However, aerobic methanotrophs were not previously identified at the ATII-I interface (Bougouffa et al., 2013). The present work revealed only one 16S rRNA pyrotag that was taxonomically assigned to uncultured aerobic methane-oxidizing bacteria in ATII-I (Table 3). The detection of a small number (or absence) of OTUs assigned to aerobic methanotrophs based on 16S rRNA gene sequences was previously reported in sediment samples from the Timor Sea methane seeps in Australia and in samples from two seep systems along the North American margin in California (Tavormina et al., 2008; Wasmund et al., 2009). It is unclear why the $16 \mathrm{~S}$ rRNA recovered from these methane seeps did not indicate the presence of the aerobic methanotrophs, whose sequences were amplified using pmoA primers (Tavormina et al., 2008, 2010). This disparity could be due to the low abundance of aerobic methanotrophs compared with the total microbial community. Alternatively, the 16S rRNA universal primers may show specificity limitations, masking the amplification of sequences from aerobic methanotrophs. This situation imposes a limitation on the 16S rRNA approach regarding the amplification and detection of sequences from aerobic methanotrophs.

Similar to these studies, the pmoA gene phylogenetic analysis provided a comprehensive understanding of the aerobic methanotrophic communities oxidizing methane seeping from this pool. The majority ( $\sim 88 \%)$ of $p m o A$ sequences from ATII-I were divergent from any known cultivated aerobic methanotroph (Supplementary Table 4). Furthermore, $\sim 32 \%$ of the pmoA sequences obtained in this study show $<90 \%$ identity with sequences in the GenBank database, suggesting that more than $25 \%$ of the aerobic methanotrophs in the ATII-I layer exhibit sequences that are largely dissimilar from all of the sequences that have been reported previously in culture-dependent or 
independent studies. The OTUs retrieved from ATII-I were clustered into four clusters within the deduced amino acid phylogenetic tree (Figure 4A). The majority of the $p m o A$ clones in the ATII-I library (ATII-I cluster 3 ) were closely related to an uncultured bacterium identified from alkaline landfill soil (Chang et al., 2010), while $\sim 28 \%$ (ATII-I cluster 2) were closely related to a novel lineage of marine-specific aerobic methanotrophs identified at different sites, including along the North American margin and Deep-Sea Methane Seeps at the Hikurangi continental margin (Tavormina et al., 2008; Ruff et al., 2013). ATII-I cluster 1 was closely related to the newly discovered bacterium Methylomarinum vadi (Hirayama et al., 2013). Interestingly, the ATII-I cluster 4 sequences shared less than 70\% identity with the best GenBank hit (Supplementary Table 4) and were phylogenetically presented as an out-group of alkane monooxygenases. The similarity of this cluster to ethylene-assimilating marine bacteria (Supplementary Table 4) Suzuki et al. (2012) suggested that these sequences belong to a unique pMMO lineage that is present in ATII-I and possibly other similar environments.

Although the Discovery Deep is also characterized by relatively high concentrations of hydrocarbons, including methane seeping from the brine to the overlaying brine-seawater interface (Faber et al., 1998; Hartmann et al., 1998; Schmidt et al., 2003), the concentration of methane in the Discovery Deep brine $(808 \mathrm{nmol} / \mathrm{l})$ is much lower compared with the Atlantis and Kebrit brines (Schmidt et al., 2003). Our approach failed to amplify pmoA from DD-I or to identify any methanotrophic-assigned OTUs in the 16S rRNA library, though one methylotrophic OTU was identified in DD-I (Figure 3A). These results are in accord with a recent study by Bougouffa and coworkers where aerobic methanotrophs were not detected in DD-I (Bougouffa et al., 2013). However, the protein-based phylogenetic analysis of our DD-I shotgun pyrosequencing metagenomic data assigned reads to methanotrophs from genera including Methylococcus, Methylacidiphilum, Methylocella, Methylosinus, Methylocystis, and Methylobacter. The methanotrophs represented $0.615 \%$ of the total significant metagenomic reads (Table 3 ). Our study addresses only a fraction of the aerobic methanotrophs because the use of the $0.1 \mu \mathrm{m}$ filter may have eliminated some aerobic methanotroph species, such as the genus Methylomonas (Dworkin et al., 2006).

Geochemical carbon isotope analyses of the Kebrit brineseawater interface point to the existence of aerobic methane oxidation (Faber et al., 1998; Antunes et al., 2011b). The microbial community living at the Kebrit brine-seawater interface was previously investigated by Eder et al. (2001), and their results did not indicate the presence of any type of methane-oxidizing bacteria (Eder et al., 2001). In the present study, both the $16 \mathrm{~S}$ rRNA and the $p m o A$ gene analyses indicated the presence of aerobic methanotrophs in the Kebrit brine-seawater interface layers and that methanotrophs similar to the genus Methylobacter represent the main aerobic methane oxidizer in these layers (Table 3, Figure 4A). Phylogenetic analysis of 16S rRNA OTUs revealed taxa that are closely related to uncultured aerobic methanotrophs from diverse marine environments as well as cultured members of the genus Methylobacter (Figure 3A). KB-U exhibited the greatest number of metagenomic reads obtained through shotgun pyrosequencing that were assigned to methanotrophs in our study. The $p m o A$ phylotypes showed that the diversity of aerobic methanotrophs in KB-U was lower than in ATII-I and was mainly dominated by methanotrophs belonging to the genus Methylobacter (Table 3, Suplementary Table 4). Similar to the samples from DD-I, no pmoA sequences were amplified from KB-L. Although KB-L exhibits a higher concentration of methane, the methanotroph abundance in this interface was shown to be very low $(\sim 0.1 \%)$ according to the $16 \mathrm{~S}$ rRNA analysis $(0.34 \%)$ based on total significant shotgun pyrosequencing metagenomic reads, and methanotrophs were undetectable in the $p m o A$ library. It was previously proposed that a high hydrogen sulfide concentration does not favor the metabolism of aerobic methanotrophs and may therefore account for their low abundance/absence in the $\mathrm{H}_{2} \mathrm{~S}$-rich KB-L (Hartmann et al., 1998; Schmidt et al., 2003).

DNA sequences encoding homologs of protein subunits of known enzymes involved in methane metabolism were detected and were similar in the KB-U and KB-L layers, which presented sequences that were distinct from those found in ATII-I and DD-I. These findings are demonstrated in the NMDS analysis (Figure 5) and in the hierarchical clustering of putative enzymes involved in methane metabolism (Supplementary Figure 1 and Table 5). The distinct pattern observed in the NMDS analysis through the ordination of putative enzymes involved in methane metabolism may not apply to other enzymatic pathways and therefore only indicates the distribution of microbes involved in methane metabolism.

The metabolic reconstruction of the putative methane metabolism pathways present in some of the obtained microbial species was based on comparing the four metagenomic libraries against the KEGG database, and the results implied that the two Kebrit layers share similar methane metabolismassociated enzymes. The number of reads associated with methane metabolism was highest in $\mathrm{KB}-\mathrm{U}$, followed by $\mathrm{KB}-\mathrm{L}$ and DD-I and, finally, ATII-I. The detection of DNA sequences that were homologous to different subunits of the key enzyme methane monooxygenase and other enzymes involved in methane oxidation in $\mathrm{KB}-\mathrm{U}$ indicates a higher abundance of aerobic methanotrophs in this layer than in all of the other layers studied, which is in agreement with the $16 \mathrm{~S}$ rRNA and protein-based phylogenetic analyses.

We primarily detected type I methanotrophs using both $16 \mathrm{~S}$ rRNA and pmoA libraries. However, the obtained shotgun pyrosequencing metagenomic reads showed hits to type II methanotrophs such as Methylocella, Methylocystis, Methylosinus, and Methylocapsa in all four libraries (Table 3). Additionally, reads presenting hits to Methylacidiphilum (Verrucomicrobia) were also detected in all four libraries (Table 3). Shotgun pyrosequencing metagenomic reads encoding sMMO homologs were identified in KB-U, KB-L, ATII-I, and DD-I. It should be noted that pMMO homologs were only identified $\mathrm{KB}-\mathrm{U}$ (Table 4).

Our results indicated that despite the low abundance of the aerobic methanotroph community in the Atlantis II Deep, Discovery Deep and Kebrit Deep brine interfaces, the diversity and novelty of the aerobic methanotrophs present, particularly 


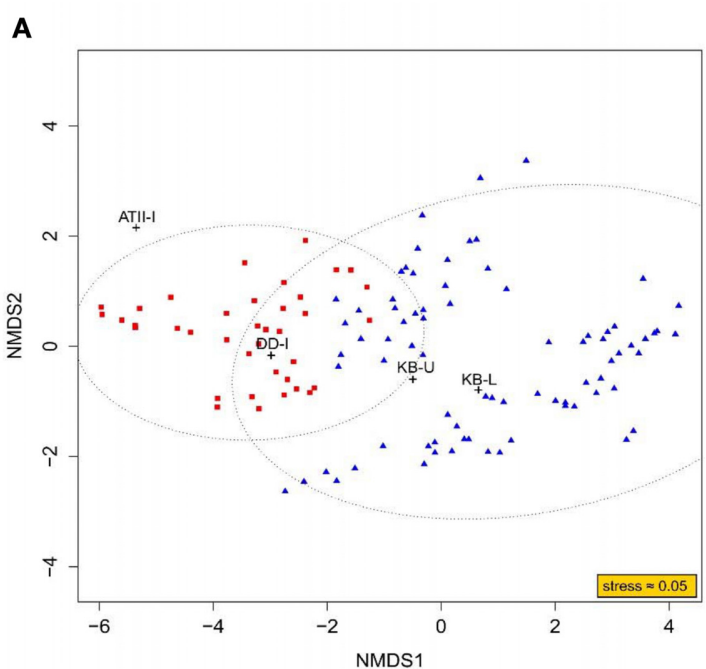

C

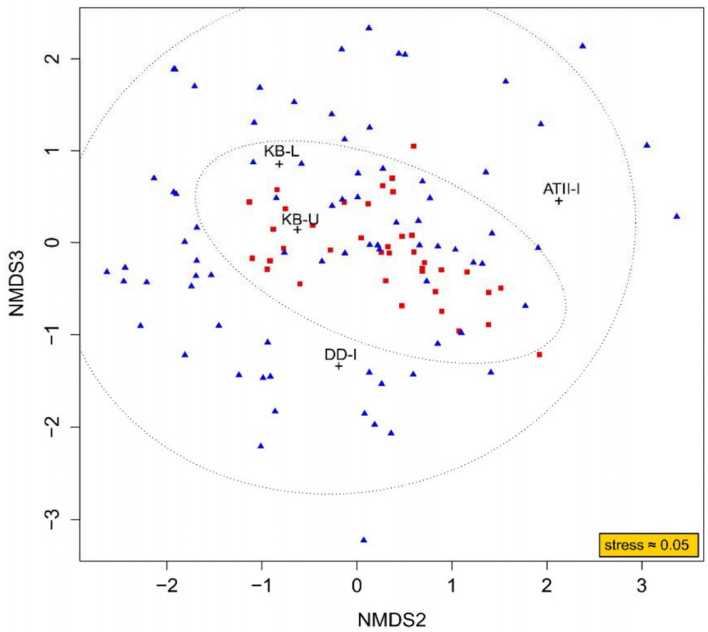

FIGURE 5 | NMDS ordination plot based on KEGG mapping to methane metabolism pathways. Representation of the NMDS analysis in $3 D(\mathbf{A}-\mathbf{C})$ and 2D (D). The analysis considers each dataset of reads obtained through Red Sea interface shotgun pyrosequencing as a variable. The read counts recruited to

methane metabolism-related KEGG orthologous groups were considered as an
B

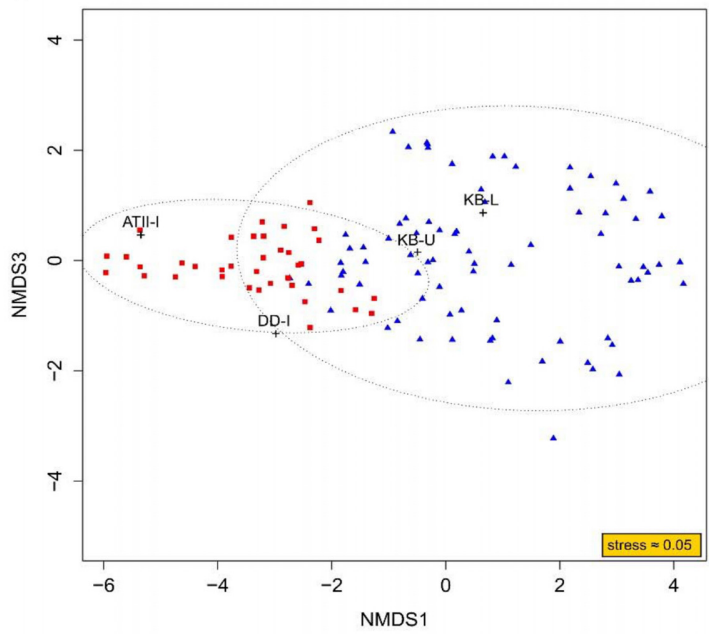

D

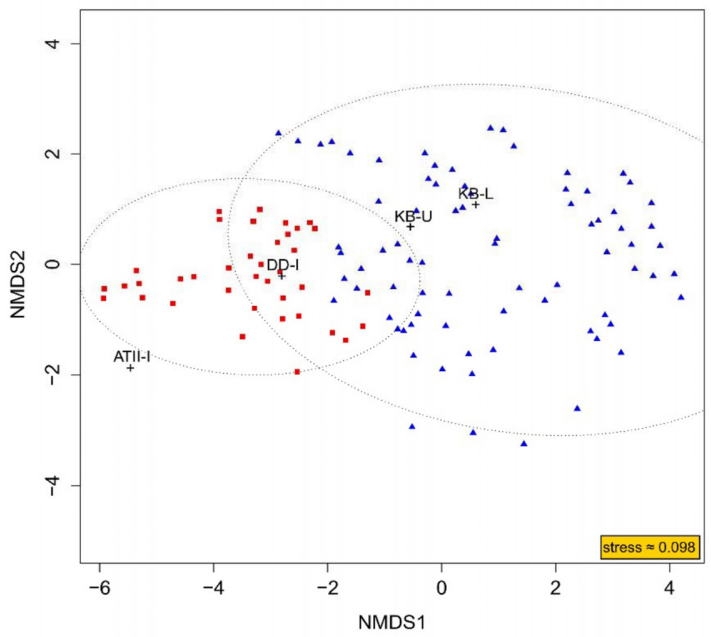

observation. The ordination of observations is represented by either blue triangles (cluster 1) or red squares (cluster 2). While the black crosses represent the ordination of variables, which is deduced from the weighted average of their respective observations. An ellipse around the centroid of each cluster depicts $95 \%$ confidence in the assignment of observations to the cluster. in ATII-I, may play a key role in methane metabolism. Our results provide additional information that could contribute to our understanding of the microbial communities existing at these "anoxic-oxic" and "brine-seawater" boundaries. Future studies on the novel aerobic methanotrophic bacteria found at ATIII and aimed at biochemical characterization of the methane monooxygenase enzymes found in Red Sea brine pools would add to our understanding on any potential novel substrate specificity.

\section{ACKNOWLEDGMENT}

This work is supported by the King Abdullah University for Science and Technology Global Collaborative Partners (GCR) program.

\section{SUPPLEMENTARY MATERIAL}

The Supplementary Material for this article can be found online at: http://www.frontiersin.org/journal/10.3389/fmicb. 2014.00487/abstract

\section{REFERENCES}

Anderson, M. J., Ellingsen, K. E., and McArdle, B. H. (2006). Multivariate dispersion as a measure of beta diversity. Ecol. Lett. 9, 683-693. doi: 10.1111/j.14610248.2006.00926.x

Antunes, A., Alam, I., El Dorry, H., Siam, R., Robertson, A., Bajic, V. B., et al. (2011a). Genome sequence of Haloplasma contractile, an unusual contractile bacterium from a deep-sea anoxic brine lake. J. Bacteriol. 193, 4551-4552. doi: 10.1128/JB.05461-11

Antunes, A., Ngugi, D. K., and Stingl, U. (2011b). Microbiology of the Red Sea (and other) deep-sea anoxic brine lakes. Environ. Microbiol. Rep. 3, 416-433. doi: 10.1111/j.1758-2229.2011.00264.x 
Belova, S. E., Baani, M., Suzina, N. E., Bodelier, P. L., Liesack, W., and Dedysh, S. N. (2011). Acetate utilization as a survival strategy of peat-inhabiting Methylocystis spp. Environ. Microbiol. Rep. 3, 36-46. doi: 10.1111/j.1758-2229.2010. 00180.x

Bougouffa, S., Yang, J. K., Lee, O. O., Wang, Y., Batang, Z., Al-Suwailem, A., et al. (2013). Distinctive microbial community structure in highly stratified deep-sea brine water columns. Appl. Environ. Microbiol. 79, 3425-3437. doi: 10.1128/AEM.00254-13

Burke, R. A. Jr., Brooks, J. M., and Sackett, W. M. (1981). Light hydrocarbons in Red Sea brines and sediments. Geochim. Cosmochim. Acta 45, 627-634. doi: 10.1016/0016-7037(81)90037-5

Caporaso, J. G., Kuczynski, J., Stombaugh, J., Bittinger, K., Bushman, F. D., Costello, E. K., et al. (2010). QIIME allows analysis of high-throughput community sequencing data. Nat. Methods 7, 335-336. doi: 10.1038/nmeth.f.303

Chang, C.-Y., Tung, H.-H., Tseng, I., Wu, J.-H., Liu, Y.-F., and Lin, H.-M. (2010). Dynamics of methanotrophic communities in tropical alkaline landfill upland soil. Appl. Soil Ecol. 46, 192-199. doi: 10.1016/j.apsoil.2010.08.009

Dedysh, S. N., Knief, C., and Dunfield, P. F. (2005). Methylocella species are facultatively methanotrophic. J. Bacteriol. 187, 4665-4670. doi: 10.1128/JB.187.13.4665-4670.2005

Dunfield, P. F., Belova, S. E., Vorob'ev, A. V., Cornish, S. L., and Dedysh, S. N. (2010). Methylocapsa aurea sp. nov., a facultative methanotroph possessing a particulate methane monooxygenase, and emended description of the genus Methylocapsa. Int. J. Syst. Evol. Microbiol. 60, 2659-2664. doi: 10.1099/ijs.0.020149-0

Dunfield, P. F., Yuryev, A., Senin, P., Smirnova, A. V., Stott, M. B., Hou, S., et al. (2007). Methane oxidation by an extremely acidophilic bacterium of the phylum Verrucomicrobia. Nature 450, 879-882. doi: 10.1038/nature06411

Dworkin, M., Falkow, S., Rosenberg, E., Schleifer, K.-H., and Stackebrandt, E. (2006). The Prokaryotes a Handbook on the Biology of Bacteria. New York, NY: Springer.

Eder, W., Jahnke, L. L., Schmidt, M., and Huber, R. (2001). Microbial diversity of the brine-seawater interface of the Kebrit Deep, Red Sea, studied via 16S rRNA gene sequences and cultivation methods. Appl. Environ. Microbiol. 67, 3077-3085. doi: 10.1128/AEM.67.7.3077-3085.2001

Edgar, R. C. (2004). MUSCLE: multiple sequence alignment with high accuracy and high throughput. Nucleic Acids Res. 32, 1792-1797. doi: 10.1093/nar/gkh340

Edgar, R. C. (2010). Search and clustering orders of magnitude faster than BLAST. Bioinformatics 26, 2460-2461. doi: 10.1093/bioinformatics/btq461

Edgar, R. C., Haas, B. J., Clemente, J. C., Quince, C., and Knight, R. (2011). UCHIME improves sensitivity and speed of chimera detection. Bioinformatics 27, 2194-2200. doi: 10.1093/bioinformatics/btr381

Elsaied, H. E., Hayashi, T., and Naganuma, T. (2004). Molecular analysis of deepsea hydrothermal vent aerobic methanotrophs by targeting genes of 16S rRNA and particulate methane monooxygenase. Mar. Biotechnol. (N.Y.) 6, 503-509. doi: 10.1007/s10126-004-3042-0

Elshahed, M. S., Youssef, N. H., Luo, Q., Najar, F. Z., Roe, B. A., Sisk, T. M., et al. (2007). Phylogenetic and metabolic diversity of Planctomycetes from anaerobic, sulfide-and sulfur-rich Zodletone Spring, Oklahoma. Appl. Environ. Microbiol. 73, 4707-4716. doi: 10.1128/AEM.00591-07

Faber, E., Botz, R., Poggenburg, J., Schmidt, M., Stoffers, P., and Hartmann, M. (1998). Methane in Red Sea brines. Org. Geochem. 29, 363-379. doi: 10.1016/S0146-6380(98)00155-7

Fisher, R. A. (1970). Statistical Methods for Research Workers. Edinburgh: Oliver \& Boyd.

Ferreira, A. J., Siam, R., Setubal, J. C., Moustafa, A., Sayed, A., Chambergo, F. S., et al. (2014). Core Microbial Functional Activities in Ocean Environments Revealed by Global Metagenomic Profiling Analyses. PLoS ONE 9:e97338. doi: 10.1371/journal.pone.0097338

Glockner, J., Kube, M., Shrestha, P. M., Weber, M., Glockner, F. O., Reinhardt, R., et al. (2010). Phylogenetic diversity and metagenomics of candidate division OP3. Environ. Microbiol. 12, 1218-1229. doi: 10.1111/j.1462-2920.2010.02164.x

Gordon, D., and Giovannoni, S. (1996). Detection of stratified microbial populations related to Chlorobium and Fibrobacter species in the Atlantic and Pacific oceans. Appl. Environ. Microbiol. 62, 1171-1177.

Guindon, S., Dufayard, J.-F., Lefort, V., Anisimova, M., Hordijk, W., and Gascuel, O. (2010). New algorithms and methods to estimate maximum-likelihood phylogenies: assessing the performance of PhyML 3.0. Syst. Biol. 59, 307-321. doi: $10.1093 /$ sysbio/syq010
Han, M. V., and Zmasek, C. M. (2009). phyloXML: XML for evolutionary biology and comparative genomics. BMC Bioinformatics 10:356. doi: 10.1186/14712105-10-356

Hanson, R. S., and Hanson, T. E. (1996). Methanotrophic bacteria. Microbiol. Rev. 60, 439-471.

Harris, J. K., Kelley, S. T., and Pace, N. R. (2004). New perspective on uncultured bacterial phylogenetic division OP11. Appl. Environ. Microbiol. 70, 845-849. doi: 10.1128/AEM.70.2.845-849.2004

Hartmann, M., Scholten, J. C., Stoffers, P., and Wehner, F. (1998). Hydrographic structure of brine-filled deeps in the Red Sea-new results from the Shaban, Kebrit, Atlantis II, and Discovery Deep. Mar. Geol. 144, 311-330. doi: 10.1016/S0025-3227(97)00055-8

Hawkins, T. L., O‘Connor-Morin, T., Roy, A., and Santillan, C. (1994). DNA purification and isolation using a solid-phase. Nucleic Acids Res. 22, 4543-4544.

Heyer, J., Galchenko, V. F., and Dunfield, P. F. (2002). Molecular phylogeny of type II methane-oxidizing bacteria isolated from various environments. Microbiology 148, 2831-2846.

Hirayama, H., Fuse, H., Abe, M., Miyazaki, M., Nakamura, T., Nunoura, T., et al. (2013). Methylomarinum vadi gen. nov., sp. nov., a methanotroph isolated from two distinct marine environments. Int. J. Syst. Evol. Microbiol. 63, 1073-1082. doi: 10.1099/ijs.0.040568-0

Horz, H. P., Rich, V., Avrahami, S., and Bohannan, B. J. (2005). Methaneoxidizing bacteria in a California upland grassland soil: diversity and response to simulated global change. Appl. Environ. Microbiol. 71, 2642-2652. doi: 10.1128/AEM.71.5.2642-2652.2005

Huse, S. M., Dethlefsen, L., Huber, J. A., Welch, D. M., Relman, D. A., and Sogin, M. L. (2008). Exploring microbial diversity and taxonomy using SSU rRNA hypervariable tag sequencing. PLoS Genet. 4:e1000255. doi: 10.1371/annotation/3d8a6578-ce56-45aa-bc71-05078355b851

Huse, S. M., Welch, D. B. M., Voorhis, A., Shipunova, A., Morrison, H. G., Eren, A. M., et al. (2014). VAMPS: a website for visualization and analysis of microbial population structures. BMC Bioinformatics 15:41. doi: 10.1186/1471-21 05-15-41

Im, J., Lee, S. W., Yoon, S., Dispirito, A. A., and Semrau, J. D. (2011). Characterization of a novel facultative Methylocystis species capable of growth on methane, acetate and ethanol. Environ. Microbiol. Rep. 3, 174-181. doi: 10.1111/j.1758-2229.2010.00204.x

Islam, T., Jensen, S., Reigstad, L. J., Larsen, O., and Birkeland, N.-K. (2008). Methane oxidation at 55 degrees $\mathrm{C}$ and $\mathrm{pH} 2$ by a thermoacidophilic bacterium belonging to the Verrucomicrobia phylum. Proc. Natl. Acad. Sci. U.S.A. 105, 300-304. doi: 10.1073/pnas.0704162105

Kato, S., Kobayashi, C., Kakegawa, T., and Yamagishi, A. (2009). Microbial communities in iron-silica-rich microbial mats at deep-sea hydrothermal fields of the Southern Mariana Trough. Environ. Microbiol. 11, 2094-2111. doi: 10.1111/j.1462-2920.2009.01930.x

Kaufman, L., and Rousseeuw, P. J. (1990). Finding Groups in Data: An Introduction to Cluster Analysis. New York, NY: Wiley.

Kumar, M. R., and Saravanan, V. (2010). Candidate OP phyla: importance, ecology and cultivation prospects. Indian J. Microbiol. 50, 474-477. doi: 10.1007/s12088011-0144-z

Maechler, M., Rousseeuw, P., And, A. S., Hubert, M., and Hornik, K. (2013). Cluster: Cluster Analysis Basics and Extensions.

McDonald, I. R., Bodrossy, L., Chen, Y., and Murrell, J. C. (2008). Molecular ecology techniques for the study of aerobic methanotrophs. Appl. Environ. Microbiol. 74, 1305-1315. doi: 10.1128/AEM.02233-07

Meyer, F., Paarmann, D., D’Souza, M., Olson, R., Glass, E. M., Kubal, M., et al. (2008). The metagenomics RAST server-a public resource for the automatic phylogenetic and functional analysis of metagenomes. BMC Bioinformatics 9:386. doi: 10.1186/1471-2105-9-386

Morris, R. M., Rappé, M. S., Connon, S. A., Vergin, K. L., Siebold, W. A., Carlson, C. A., et al. (2002). SAR11 clade dominates ocean surface bacterioplankton communities. Nature 420, 806-810. doi: 10.1038/nature01240

Moussard, H., Stralis-Pavese, N., Bodrossy, L., Neufeld, J. D., and Murrell, J. C. (2009). Identification of active methylotrophic bacteria inhabiting surface sediment of a marine estuary. Environ. Microbiol. Rep. 1, 424-433. doi: 10.1111/j.1758-2229.2009.00063.x

Murrell, J. C. (2010). "The aerobic methane oxidizing bacteria (methanotrophs)," in Handbook of Hydrocarbon and Lipid Microbiology, ed K. N. Timmis (Heidelberg: Springer), 1953-1966. 
Nercessian, O., Bienvenu, N., Moreira, D., Prieur, D., and Jeanthon, C. (2005). Diversity of functional genes of methanogens, methanotrophs and sulfate reducers in deep-sea hydrothermal environments. Environ. Microbiol. 7, 118-132. doi: 10.1111/j.1462-2920.2004.00672.x

Oksanen, J., Blanchet, F. G., Kindt, R., Legendre, P., Minchin, P. R., O’Hara, R. B., et al. (2013). Vegan: Community Ecology Package.

Oudin, E., and Thisse, Y. (1988). Geyser-type discharge in Atlantis II Deep, Red Sea: evidence of boiling from fluid inclusions in epigenetic anhydrite. Can. Mineral. 26, 765-778.

Oudin, E., Thisse, Y., and Ramboz, D. (1984). Fluid inclusion and mineralogical evidence for high-temperature saline hydrothermal circulation in the Red Sea metalliferous sediments: preliminary results. Mar. Mining 5, 3-31.

Pol, A., Heijmans, K., Harhangi, H. R., Tedesco, D., Jetten, M. S. M., and Op den Camp, H. J. M. (2007). Methanotrophy below $\mathrm{pH} 1$ by a new Verrucomicrobia species. Nature 450, 874-878. doi: 10.1038/nature06222

Price, M. N., Dehal, P. S., and Arkin, A. P. (2009). FastTree: computing large minimum evolution trees with profiles instead of a distance matrix. Mol. Biol. Evol. 26, 1641-1650. doi: 10.1093/molbev/msp077

Qian, P. Y., Wang, Y., Lee, O. O., Lau, S. C., Yang, J., Lafi, F. F., et al. (2011). Vertical stratification of microbial communities in the Red Sea revealed by $16 \mathrm{~S}$ rDNA pyrosequencing. ISME J. 5, 507-518. doi: 10.1038/ismej.2010.112

Quast, C., Pruesse, E., Yilmaz, P., Gerken, J., Schweer, T., Yarza, P., et al. (2013). The SILVA ribosomal RNA gene database project: improved data processing and web-based tools. Nucleic Acids Res. 41, D590-D596. doi: 10.1093/nar/gks1219

Rappe, M. S., Connon, S. A., Vergin, K. L., and Giovannoni, S. J. (2002). Cultivation of the ubiquitous SAR11 marine bacterioplankton clade. Nature 418, 630-633. doi: 10.1038/nature00917

R Development Core Team. (2010). R: A Language and Environment for Statistical Computing. Vienna: R Foundation for Statistical Computing.

Redmond, M. C., Valentine, D. L., and Sessions, A. L. (2010). Identification of novel methane-, ethane-, and propane-oxidizing bacteria at marine hydrocarbon seeps by stable isotope probing. Appl. Environ. Microbiol. 76, 6412-6422. doi: 10.1128/AEM.00271-10

Reed, A. J., Dorn, R., Van Dover, C. L., Lutz, R. A., and Vetriani, C. (2009). Phylogenetic diversity of methanogenic, sulfate-reducing and methanotrophic prokaryotes from deep-sea hydrothermal vents and cold seeps. Deep sea Res. II Top. Stud. Oceanogr. 56, 1665-1674. doi: 10.1016/j.dsr2.2009. 05.012

Rho, M., Tang, H., and Ye, Y. (2010). FragGeneScan: predicting genes in short and error-prone reads. Nucleic Acids Res. 38, e191. doi: 10.1093/nar/gkq747

Ruff, S. E., Arnds, J., Knittel, K., Amann, R., Wegener, G., Ramette, A., et al. (2013). Microbial communities of deep-sea methane seeps at Hikurangi continental margin (New Zealand). PLoS ONE 8:e72627. doi: 10.1371/journal.pone.0072627

Rusch, D. B., Halpern, A. L., Sutton, G., Heidelberg, K. B., Williamson, S., Yooseph, S., et al. (2007). The Sorcerer II global ocean sampling expedition: northwest Atlantic through eastern tropical Pacific. PLoS Biol. 5:e77. doi: 10.1371/journal.pbio.0050077

Schloss, P. D., Westcott, S. L., Ryabin, T., Hall, J. R., Hartmann, M., Hollister, E. B., et al. (2009). Introducing mothur: open-source, platform-independent, community-supported software for describing and comparing microbial communities. Appl. Environ. Microbiol. 75, 7537-7541. doi: 10.1128/AEM. 01541-09

Schmidt, M., Botz, R., Faber, E., Schmitt, M., Poggenburg, J., Garbe-Schönberg, D., et al. (2003). High-resolution methane profiles across anoxic brine-seawater boundaries in the Atlantis-II, discovery, and Kebrit deeps (Red Sea). Chem. Geol. 200, 359-375. doi: 10.1016/S0009-2541(03)00206-7

Shao, Z., Cui, Z., Dong, C., Lai, Q., and Chen, L. (2010). Analysis of a PAH-degrading bacterial population in subsurface sediments on the MidAtlantic Ridge. Deep Sea Res. I Oceanogr. Res. Pap. 57, 724-730. doi: 10.1016/j.dsr.2010.02.001

Siam, R., Mustafa, G. A., Sharaf, H., Moustafa, A., Ramadan, A. R., Antunes, A., et al. (2012). Unique prokaryotic consortia in geochemically distinct sediments from Red Sea Atlantis II and discovery deep brine pools. PLoS ONE 7:e42872. doi: 10.1371/journal.pone.0042872

Sogin, M. L., Morrison, H. G., Huber, J. A., Welch, D. M., Huse, S. M., Neal, P. R., et al. (2006). Microbial diversity in the deep sea and the underexplored "rare biosphere." Proc. Natl. Acad. Sci. U.S.A. 103, 12115-12120. doi: $10.1073 /$ pnas.0605127103
Söhngen, N. (1906). Über bakterien, welche methan als kohlenstoffnahrung und energiequelle gebrauchen. Zentralbl. Bakteriol. Parasitenkd. Infektionskr. 15, 513-517.

Stamatakis, A. (2006). RAxML-VI-HPC: maximum likelihood-based phylogenetic analyses with thousands of taxa and mixed models. Bioinformatics 22, 2688-2690. doi: 10.1093/bioinformatics/btl446

Stoecker, K., Bendinger, B., Schöning, B., Nielsen, P. H., Nielsen, J. L., Baranyi, C., et al. (2006). Cohn's Crenothrix is a filamentous methane oxidizer with an unusual methane monooxygenase. Proc. Natl. Acad. Sci. U.S.A. 103, 2363-2367. doi: 10.1073/pnas.0506361103

Stoffers, P., Moammar, M., Abu-Ouf, M., Ackermand, D., Alassif, O., Al-Hazim, Y., et al. (1998). Hydrography, Hydrothermalism and Paleoceanography in the Red Sea. Kiel: Geologisch-Paläontologisches Institut der Unive rsität Kiel.

Suzuki, R., and Shimodaira, H. (2006). Pvclust: an R package for assessing the uncertainty in hierarchical clustering. Bioinformatics 22, 1540-1542. doi: 10.1093/bioinformatics/btl117

Suzuki, T., Nakamura, T., and Fuse, H. (2012). Isolation of two novel marine ethylene-assimilating bacteria, Haliea species ETY-M and ETY-NAG, containing particulate methane monooxygenase-like genes. Microbes Environ. 27, 54-60. doi: 10.1264/jsme2.ME11256

Swift, S. A., Bower, A. S., and Schmit, R. W. (2012). Vertical, horizontal, and temporal changes in temperature in the Atlantis II and Discovery hot brine pools, Red Sea. Deep Sea Res. I Oceanogr. Res. Pap. 64, 118-128. doi: 10.1016/j.dsr.2012.02.006

Tavormina, P. L., Orphan, V. J., Kalyuzhnaya, M. G., Jetten, M. S. M., and Klotz, M. G. (2011). A novel family of functional operons encoding methane/ammonia monooxygenase-related proteins in gammaproteobacterial methanotrophs. Environ. Microbiol. Rep. 3, 91-100. doi: 10.1111/j.1758-2229.2010. 00192.x

Tavormina, P. L., Ussler, W., Joye, S. B., Harrison, B. K., and Orphan, V. J. (2010). Distributions of putative aerobic methanotrophs in diverse pelagic marine environments. ISME J. 4, 700-710. doi: 10.1038/ismej. 2009.155

Tavormina, P. L., Ussler, W. 3rd., and Orphan, V. J. (2008). Planktonic and sediment-associated aerobic methanotrophs in two seep systems along the North American margin. Appl. Environ. Microbiol. 74, 3985-3995. doi: 10.1128/AEM.00069-08

Tavormina, P. L., Ussler, W., Steele, J. A., Connon, S. A., Klotz, M. G., and Orphan, V. J. (2013). Abundance and distribution of diverse membrane-bound monooxygenase (Cu-MMO) genes within the Costa Rica oxygen minimum zone. Environ. Microbiol. Rep. 5, 414-423. doi: 10.1111/1758-2229.12025

Vigliotta, G., Nutricati, E., Carata, E., Tredici, S. M., De Stefano, M., Pontieri, P., et al. (2007). Clonothrix fusca Roze 1896, a filamentous, sheathed, methanotrophic gamma-proteobacterium. Appl. Environ. Microbiol. 73, 3556-3565. doi: 10.1128/AEM.02678-06

von der Weid, I., Korenblum, E., Jurelevicius, D., Rosado, A. S., Dino, R., Sebastian, G. V., et al. (2008). Molecular diversity of bacterial communities from subseafloor rock samples in a deep-water production basin in Brazil. J. Microbiol. Biotechnol. 18, 5-14.

Vorobev, A. V., Baani, M., Doronina, N. V., Brady, A. L., Liesack, W., Dunfield, P. F., et al. (2011). Methyloferula stellata gen. nov., sp. nov., an acidophilic, obligately methanotrophic bacterium that possesses only a soluble methane monooxygenase. Int. J. Syst. Evol. Microbiol. 61, 2456-2463. doi: 10.1099/ijs.0. 028118-0

Wang, P., Wang, F., Xu, M., and Xiao, X. (2004). Molecular phylogeny of methylotrophs in a deep-sea sediment from a tropical west Pacific Warm Pool. FEMS Microbiol. Ecol. 47, 77-84. doi: 10.1016/S0168-6496(03)00252-6

Warnes, G. R., Bolker, B., Bonebakker, L., Gentleman, R., Huber, W., Liaw, A., et al. (2011). Gplots: Various R Programming Tools for Plotting Data.

Wasmund, K., Kurtboke, D. I., Burns, K. A., and Bourne, D. G. (2009). Microbial diversity in sediments associated with a shallow methane seep in the tropical Timor Sea of Australia reveals a novel aerobic methanotroph diversity. FEMS Microbiol. Ecol. 68, 142-151. doi: 10.1111/j.1574-6941.2009. 00667.x

Yan, T., Ye, Q., Zhou, J., and Zhang, C. L. (2006). Diversity of functional genes for methanotrophs in sediments associated with gas hydrates and hydrocarbon seeps in the Gulf of Mexico. FEMS Microbiol. Ecol. 57, 251-259. doi: 10.1111/j.1574-6941.2006.00122.x 
Conflict of Interest Statement: The authors declare that the research was conducted in the absence of any commercial or financial relationships that could be construed as a potential conflict of interest.

Received: 09 June 2014; accepted: 28 August 2014; published online: 23 September 2014.

Citation: Abdallah RZ, Adel M, Ouf A, Sayed A, Ghazy MA, Alam I, Essack M, Lafi FF, Bajic VB, El-Dorry H and Siam R (2014) Aerobic methanotrophic communities at the Red Sea brine-seawater interface. Front. Microbiol. 5:487. doi: 10.3389/fmicb. 2014.00487
This article was submitted to Aquatic Microbiology, a section of the journal Frontiers in Microbiology.

Copyright (C) 2014 Abdallah, Adel, Ouf, Sayed, Ghazy, Alam, Essack, Lafi, Bajic, El-Dorry and Siam. This is an open-access article distributed under the terms of the Creative Commons Attribution License (CCBY). The use, distribution or reproduction in other forums is permitted, provided the original author(s) or licensor are credited and that the original publication in this journal is cited, in accordance with accepted academic practice. No use, distribution or reproduction is permitted which does not comply with these terms. 